\title{
El mercado de
}

\section{trabajo argentino en la globalización financiera}

\author{
Mario Damill y Roberto Frenkel
}

I

experiencia argentina de las últimas décadas en materia de generación de empleo y salarios ha sido muy decepcionante, y ha tenido claras consecuencias sobre la distribución del ingreso y otros indicadores sociales. Este trabajo examina la evolución del mercado de trabajo, poniendo el acento en la década de 1990, y aborda también los notables cambios que se han venido produciendo en los últimos años, luego de la crisis del régimen de convertibilidad. En general, postula que la evolución observada en el mercado de trabajo y en la distribución del ingreso se vincula muy estrechamente con la evolución macroeconómica, tanto en fases anteriores como en la reciente recuperación. Examina en especial los efectos negativos que tuvieron las experiencias de apertura comercial con apreciación cambiaria de fines de la década de 1970 y en el decenio de 1990, los que contrastan marcadamente con lo que viene observándose en la actualidad, en particular en materia de generación de puestos de trabajo. 


\section{I}

\section{Introducción}

La economía argentina ha mostrado a lo largo de varias décadas un desempeño muy insatisfactorio en materia de generación de puestos de trabajo, tanto en cantidad como en calidad. Se ha observado también una tendencia declinante de largo plazo de los salarios reales medios y un sostenido empeoramiento de la distribución del ingreso.

Nuestro argumento más general es que esos rasgos del mercado de trabajo y de la distribución del ingreso se vinculan estrechamente con la evolución macroeconómica. Desde mediados del decenio de 1970, en particular, y salvo en algunos períodos relativamente breves, las condiciones laborales han sido afectadas negativamente por un conjunto de factores macroeconómicos: la inestabilidad del producto interno bruto (PIB), su bajo crecimiento de largo plazo, la elevada inflación, las frecuentes oscilaciones de los precios relativos asociadas a sucesivos intentos de estabilización y a sus fracasos, y un prolongado período de apreciación cambiaria. Merecen mención especial los efectos desfavorables que tuvieron sobre el empleo las experiencias de apertura comercial con apreciación cambiaria de fines del decenio de 1970 y del decenio de 1990, así como las crisis por las que atravesó la economía nacional.

Las características de la evolución macroeconómica del país en este período resultaron de la confluencia de procesos de reforma, políticas de estabilización e importantes cambios en el contexto internacional. Las reformas y las políticas macroeconómicas adoptadas definieron la forma particular en que la economía nacional fue articulándose con el nuevo marco financiero externo, durante la fase que se conoce como la segunda globalización financiera. En suma, las mencionadas tendencias del empleo y la distribución están asociadas con la trayectoria de integración internacional seguida por el país desde mediados de la década de 1970.

$\square$ Una versión más extensa de este trabajo fue presentada en la conferencia internacional "La globalización y el desarrollo nacional: hacia una mayor coherencia entre las políticas económicas y laborales" (Buenos Aires, agosto de 2005), organizada por la OIT.
En la historia macroeconómica del período se pueden distinguir, a grandes rasgos, cuatro fases principales. Una primera etapa, de desregulación y apertura comercial y financiera, se extendió entre 1977 y 1982. Acabó en una crisis cambiaria, financiera y de deuda y fue seguida por un cierre de los mercados externos de fondos, o racionamiento del crédito internacional, desde 1982 hasta 1990. Sobrevendría luego una nueva fase de desregulación y apertura comercial y financiera, que se correspondió con la vigencia del régimen de convertibilidad, entre 1991 y 2001. También esta fase acabó en crisis e incumplimiento de pagos. A estos últimos episodios siguió el período actual de recuperación económica. En suma, las dos experiencias de apertura comercial y financiera desembocaron en graves crisis bancarias, cambiarias y de deuda, mientras que la etapa intermedia, de racionamiento del crédito, concluyó en los episodios de hiperinflación de 1989 y 1990.

En este trabajo nos concentraremos en el análisis de lo sucedido desde comienzos de la década de 1990, prestando especial atención a los procesos asociados a la dinámica macroeconómica bajo el régimen de convertibilidad y a sus efectos sobre el mercado de trabajo. Examinaremos también las principales características de la fase actual, posterior a la crisis de 2001-2002. Sin embargo, debe resaltarse que algunos de los rasgos estilizados más importantes del comportamiento macroeconómico en el decenio de 1990 se asemejan a lo observado en la anterior experiencia de apertura, a fines de la década de 1970. Ambas etapas pueden interpretarse a partir de un modelo común, y lo mismo puede decirse de varias experiencias comparables de otras economías, en especial de América Latina. Ese modelo común, así como el análisis comparativo de las experiencias señaladas, han sido desarrollados en otros trabajos, por lo que no lo expondremos en detalle aquí. ${ }^{1}$ Con ese marco interpretativo como telón de fondo, la sección II del trabajo, que sigue a esta introducción, presenta los hechos estilizados

\footnotetext{
${ }^{1}$ Véase, por ejemplo, Frenkel (2003a y 2003b) y Damill, Frenkel y Rapetti (2005).
} 
propios de la macroeconomía argentina en el decenio de 1990, incluyendo la crisis final del plan de convertibilidad y también la descripción de los rasgos principales de la recuperación económica posterior a la crisis.

La sección III contiene el análisis de la evidencia cuantitativa acerca de los impactos de la evolución macroeconómica sobre el empleo, el desempleo y las remuneraciones, con acento en el período 1991-2002. En esta sección se analizan ante todo, con algún detalle, los efectos esperables de la combinación de un tipo de cambio apreciado y la apertura comercial. Luego se describe la evolución del empleo agregado, del subempleo y del desempleo en el decenio de 1990. En seguida se enfoca el comportamiento de las mismas variables en la fase reciente de recuperación. Se presenta un modelo cuantitativo para estimar el impacto agregado de la evolución de la actividad económica y los precios relativos sobre la ocupación, presentando un análisis que comprende el período de convertibilidad y la fase de recuperación. Se describe la composición de la contracción del empleo en la década de 1990, mostrando que ésta se originó principalmente en los sectores comerciables. Finalmente, se completa el análisis estudiando la evolución de los ingresos y presentando estimaciones de curvas de salarios en función de las tasas de desempleo, en el período de convertibilidad y también en la fase de recuperación.

\section{II}

\section{La dinámica macroeconómica argentina en el decenio de 1990}

\section{El desempeño bajo el régimen de convertibilidad}

Durante el último tercio del siglo XX se desarrolló en el mundo el proceso conocido como segunda globalización financiera. En esta nueva etapa de la evolución financiera internacional, varios países latinoamericanos y de otras regiones experimentaron crisis externas y financieras con dramáticos efectos reales. Estos episodios involucraron generalmente altos costos económicos y sociales y retrocesos en el crecimiento. Las crisis de México (1994-1995), Argentina (1995), Brasil (1998-1999) y nuevamente Argentina (2001-2002) estallaron en los países latinoamericanos que habían recibido los mayores flujos de capital en las fases de auge previas. Estos países son, a su vez, las economías de mayor tamaño y los mayores "mercados emergentes" constituidos en la región.

Las distintas experiencias nacionales referidas conjugaron la aplicación de reformas como la apertura comercial y la apertura y liberalización de la cuenta de capital - junto con privatizaciones, reformas fiscales y medidas de desregulación en otros mercados- con políticas macroeconómicas antiinflacionarias en las que el tipo de cambio fijo o cuasi fijo desempeñaba un papel crucial. México puso en práctica un programa de este tipo en 1988, Argentina en 1991 y Brasil en 1994.
Un examen somero de esos casos permite identificar un conjunto de rasgos comunes de los contextos institucionales y de política económica en que se presentaron las crisis: i) el tipo de cambio nominal era fijo o cuasi fijo; ii) el tipo de cambio real estaba apreciado; iii) prácticamente no existían barreras al libre movimiento de capitales; iv) las entradas de capitales en el período de auge previo fueron de gran magnitud en comparación con el tamaño de los mercados nacionales de dinero y capital preexistentes, y v) la regulación de los sistemas financieros nacionales en la etapa de auge fue relativamente débil y permisiva.

Las experiencias mencionadas muestran, en todos los casos, además de esas características, una dinámica macroeconómica de ciclo, con una fase inicial expansiva, seguida de un período de estancamiento o recesión, una creciente fragilidad financiera y externa $\mathrm{y}$, finalmente, la crisis financiera y cambiaria. ${ }^{2}$

Bajo el esquema de estabilización con ancla cambiaria y apertura comercial y financiera adoptado por Argentina en la década de 1990, con el plan de convertibilidad, se observaron también los rasgos

\footnotetext{
2 La descripción estilizada del ciclo se presenta, por ejemplo, en Frenkel (2003a y 2003b), en Damill, Frenkel y Maurizio (2003), y en Damill y Frenkel (2005). Véase también Taylor (1998).
} 
señalados, así como la dinámica cíclica. Sin embargo, el ciclo de apertura-expansión, seguido de aumento de la fragilidad financiera externa, contracción y crisis, fue experimentado por el país dos veces en la década. Primero entre 1990 y 1995 (año en que la economía fue frenada por el efecto de derrame de la crisis de México), y luego entre 1995 y 2001 (gráfico 1). El primero de esos ciclos no desembocó en crisis cambiaria, aunque sí en recesión y crisis financiera.

Los diversos cambios positivos ocurridos en el contexto financiero internacional tuvieron un fuerte impacto en el plano interno al inicio del período. Las tasas internacionales de interés cayeron abruptamente a partir de 1989, al tiempo que se recuperaba el acceso al financiamiento externo. En 1991 los ingresos de capitales comenzaron a adquirir importancia. Además de los factores de expulsión, que explicaron buena parte de la afluencia de capitales hacia los mercados emergentes (especialmente la caída de las tasas de interés en el mundo desarrollado), también fueron importantes los factores internos, llamados "de atracción": en el caso argentino cabe destacar el proceso de privatizaciones, iniciado en 1990, la liberalización financiera y el lanzamiento del programa de estabilización. Así, en los primeros años de la década, los ingresos netos de fondos superaron al déficit en cuenta corriente, permitiendo una sustancial y rápida acumulación de reservas internacionales, cuyo acervo inicial era muy pequeño. La acumulación de reservas alimentó el incremento de la cantidad de dinero y de crédito y esto, combinado con la declinación de las tasas de interés (externas e internas), llevó a una rápida expansión de la demanda agregada y el PIB. El incremento del PIB, a su vez, afectó al balance de pagos, puesto que estimuló las importaciones, contribuyendo al déficit en la cuenta corriente. La apertura comercial y la apreciación cambiaria actuaron en el mismo sentido.

El crecimiento liderado por los ingresos de capitales continuó hasta 1994. En ese año se produjo un alza de las tasas de interés internacionales (a partir de la decisión de la Reserva Federal de elevar sus tasas de descuento a partir de febrero). Esto comenzó a gravitar negativamente sobre la afluencia de fondos y, debido al déficit cada vez mayor de la cuenta corriente, las reservas de divisas dejaron de crecer.

Cabe resaltar que, en esta primera etapa, el programa de estabilización mostró una gran eficacia antiinflacionaria. La desaceleración de los precios posterior a su lanzamiento fue inmediata. En el caso de los bienes comerciables en el ámbito internacional, de los cuales da cuenta de manera aproximada el índice de precios mayoristas, la fijación del tipo de cambio tuvo un impacto notable. La inflación mayorista bajó inmediatamente a cifras del orden del 1\% mensual, y siguió en declinación. Este índice acumularía una variación de $12,5 \%$ desde el inicio del plan hasta diciembre de 1994, lo que equivale a poco más de $3 \%$ en términos anualizados, en línea con la inflación internacional, medida, por ejemplo, por el índice de precios al consumidor de los Estados Unidos.

GRÁFICO 1

Argentina: Producto interno bruto, 1991-2005a

(A precios constantes de 1993)

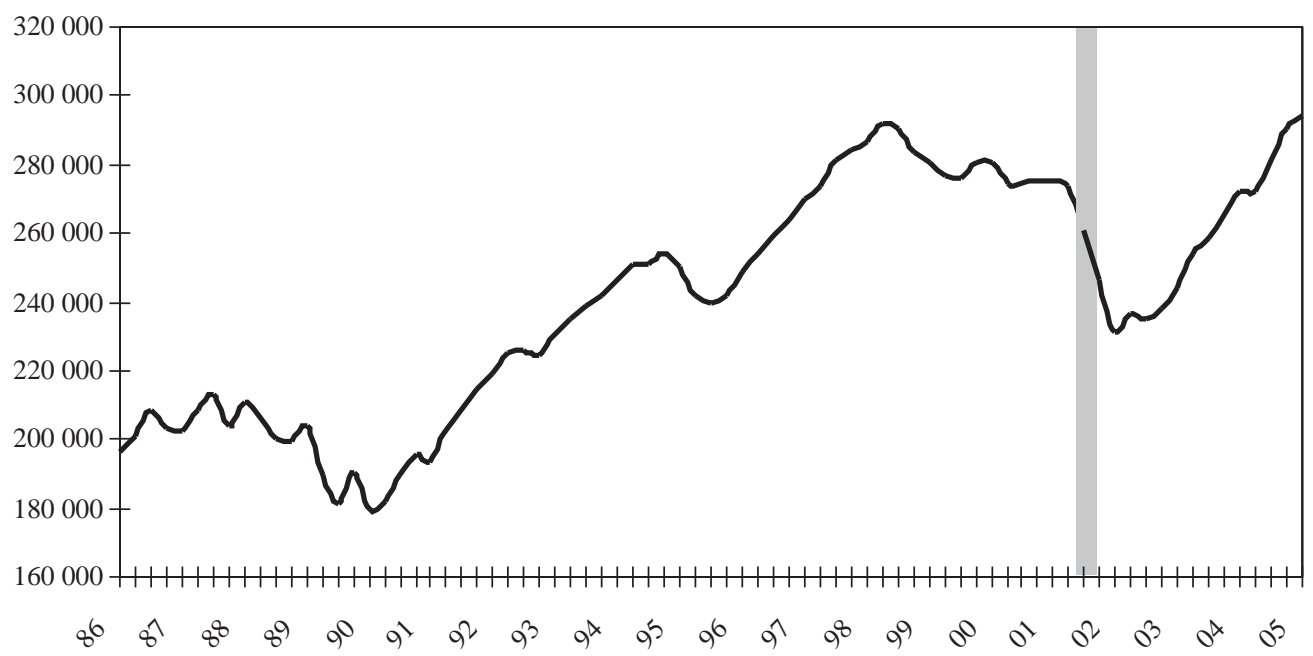

Fuente: Elaboración propia basada en cifras del Ministerio de Economía y Producción.

a Datos trimestrales desestacionalizados. 
GRÁFICO 2

Argentina: Tipo de cambio real, ${ }^{\mathrm{a}}$ 1986-2002 (Segundo semestre de $1986=1$ )

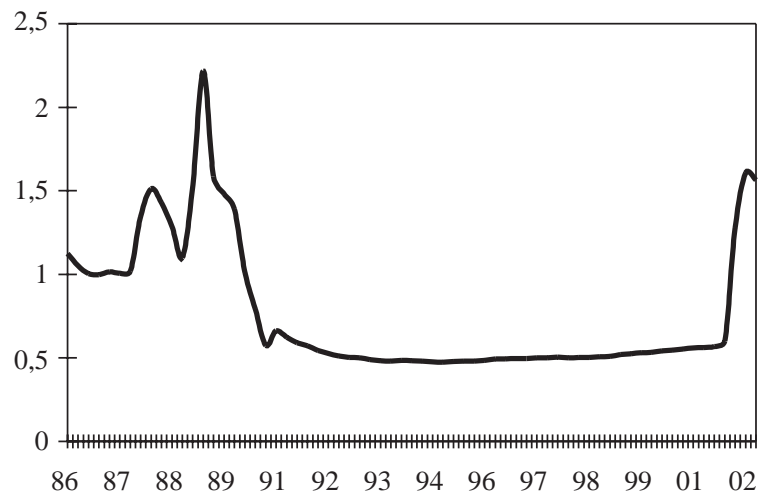

Fuente: Elaboración propia sobre la base de cifras del Instituto Nacional de Estadística y Censos (INDEC) y del Banco Central.

a Tipo de cambio nominal multiplicado por el índice de precios al consumidor (IPC) de los Estados Unidos, sobre el IPC local.

El índice de precios al consumidor argentino, en cambio, subió 58,5\% en el mismo lapso. Aunque también en este caso la caída del ritmo inflacionario fue abrupta, la inflación residual que se acumuló en los primeros tres años no era despreciable. Esto se explica por el mayor peso que tienen los bienes y servicios no comerciables en el cálculo del IPC, y expresa, en consecuencia, el cambio de precios relativos ocurrido en el período. La divergencia entre estos dos índices de precios desapareció hacia fines de 1994. Desde ese momento y hasta la crisis final del régimen macroeconómico, en diciembre de 2001, las tasas de inflación tendieron a ubicarse siempre muy próximas a cero, y con predominio de leves variaciones negativas.

El gráfico 2 y el cuadro 1 presentan información relativa a la evolución del tipo de cambio real. Es importante destacar que esta variable, que había alcanzado niveles extraordinariamente altos durante los episodios de corrida cambiaria que detonaron las crisis hiperinflacionarias de 1989 y 1990, declinó verticalmente a lo largo de este último año, es decir, antes del lanzamiento del plan de convertibilidad.

Como se observa en el cuadro 1, ya en el lapso inmediatamente anterior al lanzamiento del programa de estabilización la paridad real se ubicaba casi $50 \%$ por debajo de su nivel medio del período 1986-1990. Comparada con esa declinación, la observada a partir del segundo trimestre de 1991 puede considerarse de orden secundario. Luego siguió una larga fase de estabilidad, en la cual las variaciones de la paridad real
CUADRO 1

Argentina: Tipo de cambio real medio de diferentes períodos

(Segundo semestre de 1986=1)

Período

Tipo de cambio real

1986-1988

1986-1990

1,16

1990:4-1991:1

$1991: 2-1994: 4^{\text {a }}$

1995-2001

2002

1,22

0,62

0,52

0,52

1,48

Fuente: Elaboración propia con datos del INDEC y del Banco Central.

a Trimestres.

GRÁFICO 3

Argentina: Salario real medio en las manufacturas y salario medio en dólares de poder adquisitivo constante, 1986-2001

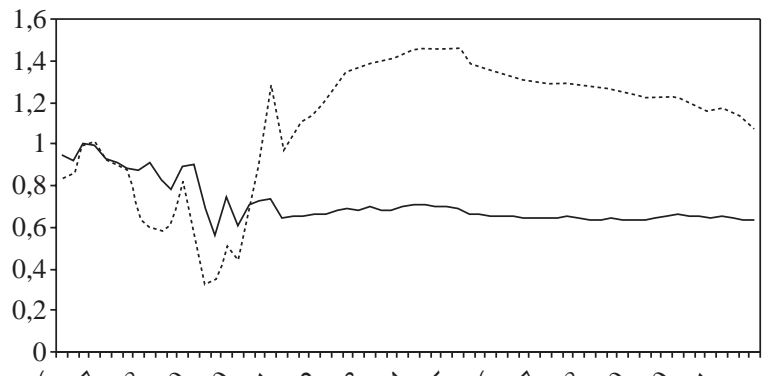

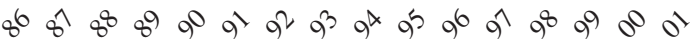

$$
\text { Salario real …...... Salario en dólares constantes }
$$

Fuente: Elaboración propia con datos del INDEC.

fueron muy pequeñas, hasta la quiebra del régimen monetario en diciembre de 2001.

El gráfico 3 y el cuadro 2 presentan los datos relativos a los salarios en dólares y a los salarios reales medios en el sector manufacturero. Nuevamente se destaca, en el caso del salario en dólares, el drástico cambio de inicio de período. El aumento de las remuneraciones medidas en esa moneda supera el $50 \%$, cuando se compara el nivel registrado en el período anterior al lanzamiento del plan con el promedio de 1986-1990. Aquí también las variaciones posteriores pueden considerarse de segundo orden.

El salario real en las manufacturas, en cambio, tuvo un comportamiento muy diferente, que reflejó también el proceso de apreciación cambiaria. Puesto que los precios de los bienes y servicios no comerciables subieron considerablemente medidos en dólares, 
Argentina: Salarios medios en la manufactura en diferentes períodos (Segundo semestre de $1986=100$ )

\begin{tabular}{lccrr}
\hline Período & $1986-1988$ & $1986-1990$ & $1990: 4-1991: 1$ & $1991: 2-1994: 4$ \\
\hline Salario real a $^{\text {a }}$ & 90,8 & 82,9 & 68,8 & 68,4 \\
Salario en dólares $^{\text {b }}$ & 80,6 & 73,9 & 112,3 & 134,8 \\
\hline
\end{tabular}

Fuente: Elaboración propia con datos del INDEC.

a Salario medio deflactado por el IPC.

b Salario medio en dólares de poder adquisitivo constante (deflactado por el índice de precios al consumidor de los Estados Unidos).

y que estos bienes y servicios tenían un peso elevado en el IPC, el salario deflactado por este índice apenas ascendió levemente al inicio del programa de estabilización, tras haber sufrido una caída en los meses anteriores. Luego de un alza moderada en los primeros años de la convertibilidad, el salario real medio en la industria manufacturera presentó una leve tendencia contractiva a lo largo de la segunda mitad de la década.

A lo largo de la fase expansiva que se extendió entre 1990 y 1994, la vulnerabilidad de la economía a shocks externos desfavorables se incrementó. El déficit en cuenta corriente tendió a aumentar al tiempo que crecía el endeudamiento externo. Así, la dependencia en relación con los ingresos de fondos se acentuó. En otras palabras, el esquema macroeconómico se tornó más vulnerable a cambios que pudieran afectar más o menos abruptamente la disponibilidad de financiamiento externo. Esta fuente de vulnerabilidad se hizo más notoria en el caso argentino, debido a que el régimen involucraba una completa liberalización de las corrientes de capitales.

El alza de las tasas de interés internacionales experimentada en 1994, ya mencionada, así como sus consecuencias sobre la afluencia de capitales y la mecánica propia del régimen de convertibilidad, podrían haber conducido por sí solas a una fase contractiva. Pero a fines de ese año México sufrió una corrida contra el peso que concluyó en una fuerte depreciación. El contagio afectó inmediatamente a Argentina. Por lo tanto, en lugar de experimentar este país un ajuste endógeno según el mecanismo típico de un régimen de caja de conversión, el shock externo llevó a una masiva y rápida salida de fondos a comienzos de 1995, con un incremento paralelo, muy acentuado, de las tasas de interés internas. El acervo de reservas se redujo bruscamente y, con ello, se contrajo la liquidez. La demanda agregada mostró un comportamiento similar. En esta fase, la tasa de desempleo (que ya había iniciado, en realidad, una tendencia ascendente dos años antes, cuando todavía la economía se expandía a un ritmo muy intenso) experimentó un sustancial aumento, ubicándose siempre, desde allí en adelante, en niveles históricamente muy elevados.

Con todo, la recesión de mediados de la década fue muy breve. Un potente conjunto de medidas de apoyo financiero externo e interno, estructurado con la coordinación del Fondo Monetario Internacional (FMI), permitió cambiar rápidamente el cariz negativo de las expectativas. Además, por distintos mecanismos, y a pesar de las limitaciones establecidas por la regla de convertibilidad, el gobierno desplegó un intenso activismo monetario dirigido a sostener a los bancos y detener así la profundización de la crisis financiera.

Debido a los efectos favorables del apoyo financiero externo fue posible preservar el régimen monetario. Ya hacia el cierre de 1995 una nueva expansión estaba iniciándose. El mecanismo monetario por detrás de esta recuperación fue el mismo que se había utilizado en los años tempranos de la década de 1990. Se reabrió el acceso a los fondos del exterior; la afluencia de capitales comenzó a superar al déficit de la cuenta corriente (que se había reducido como consecuencia de la recesión), y las reservas de divisas repuntaron otra vez, al igual que las cantidades de dinero y crédito. Los elementos de la dinámica cíclica estaban nuevamente en movimiento.

Esta nueva fase expansiva mostraría rasgos estilizados semejantes a los de la primera, pero resultaría más corta. La prima de riesgo subió a mediados de 1997, luego de la devaluación tailandesa, y el crecimiento se desaceleró. La crisis rusa de 1998, que también tuvo un muy fuerte impacto en Brasil, llevó la expansión a su final. Los ingresos de fondos declinaron desde ese momento y la acumulación de reservas se desaceleró, para tornarse negativa algo más adelante. Como consecuencia, a mediados de 1998 se inició una fase de contracción del PIB, que concluiría con el colapso de 2001-2002, en el que, entre otros numerosos 
acontecimientos, se experimentó la violenta depreciación del peso ya mencionada, y la cesación de pagos frente a buena parte de los compromisos financieros externos e internos del gobierno.

El guión argumental de la historia macroeconómica de los años tardíos del decenio de 1990 es bastante simple. Para comenzar, el giro desfavorable del escenario financiero externo experimentado en 19971998, luego de las crisis del sudeste de Asia y de Rusia, encontró a Argentina con un déficit en cuenta corriente alto y creciente, una moneda apreciada y una perceptible carencia de instrumentos de política para hacer frente a ese conjunto de problemas, dada la rigidez del esquema macroeconómico adoptado. No sorprende que, en esas condiciones, la prima de riesgo-país haya subido bruscamente y haya permanecido así y que el acceso a fondos del exterior se haya tornado más y más problemático. El subsiguiente aumento de la carga de intereses de la deuda tuvo un impacto negativo sobre todos los deudores, incluyendo naturalmente al sector público.

Ante la carencia de otros instrumentos, el gobierno respondió a esa situación con políticas fiscales restrictivas. La historia oficial en relación con esta forma de activismo solía rezar así: la disciplina fiscal restaurará la confianza en la capacidad de pagos del sector público, de manera que la prima de riesgo sobre la deuda soberana caerá, llevando a una declinación de las tasas de interés internas. Por lo tanto, la demanda interna de bienes y servicios se recuperará, sacando a la economía del pozo recesivo. Menores tasas de interés y un mayor nivel del PIB contribuirán, a su vez, a equilibrar las cuentas públicas, lo que también alimentará nuevamente la confianza, cerrando así un círculo virtuoso.

La historia macroeconómica de los últimos años de la década de 1990 es la historia del fracaso de esa visión. A pesar del perceptible ajuste del resultado primario del sector público que se produjo en esos años, el canal de crédito no pudo reabrirse. Más aún, las alzas de impuestos y los recortes del gasto público reforzaron las tendencias recesivas, contribuyendo con ello a consolidar las expectativas negativas que impedían la tan esperada declinación de la prima de riesgo-país.

Resulta evidente que la política fiscal por sí sola fue impotente para compensar los fuertes desequilibrios macroeconómicos que tenían raíces en otro lugar, más precisamente, en el sector externo. Bajo esta orientación de política fiscal autodestructiva, la economía quedó atrapada en un círculo vicioso por varios años, sufriendo así la más prolongada recesión desde la primera guerra mundial. ${ }^{3}$

\section{La macroeconomía después de la cesación de pagos y la devaluación}

Luego de tres años de recesión, la actividad económica sufrió una abrupta caída adicional desde mediados de 2001. La masiva huida hacia activos externos que tuvo lugar en el segundo semestre de ese año precipitó el colapso del régimen de convertibilidad y desembocó en el incumplimiento de pagos y la devaluación del peso. La fuerte declinación de las reservas de divisas experimentada a lo largo de ese año comprimió rápidamente la liquidez. Luego de implantada una serie de restricciones al retiro de depósitos del público en los bancos (el "corralito") se produjo una verdadera interrupción de la cadena de pagos. El PIB y el empleo acompañaron la trayectoria de violenta contracción de las reservas de divisas y la liquidez. Indicadores sociales como las tasas de desempleo y los índices de incidencia de la pobreza y la indigencia, que habían desmejorado considerablemente a lo largo de la década de 1990, sufrieron un nuevo y brusco deterioro adicional, alimentando también las tensiones sociales y la crisis política que puso fin al gobierno de la Alianza (Damill, Frenkel y Maurizio, 2003).

\section{a) La recuperación económica}

La caída vertical del producto y del empleo continuó luego de la ruptura de la convertibilidad, pero solo por un muy breve período. En efecto, contrariando la mayor parte de las opiniones y creencias, incluidas las de diversos funcionarios del FMI, los traumáticos episodios políticos y económicos que pusieron fin al régimen de convertibilidad no fueron seguidos por una depresión aún más profunda, sino por una recuperación extraordinariamente veloz, que se inició apenas un trimestre después de esos eventos.

En el gráfico 1, que vimos más atrás, se constata la trayectoria en $\mathrm{V}$ configurada por la fase de colapso económico de los últimos trimestres de la convertibilidad y por el rápido repunte posterior. Como acabamos de señalar, el repunte del PIB se inició muy poco después de la depreciación cambiaria que puso fin a la década de convertibilidad (unos tres meses después, según puede verse en los indicadores mensuales de

\footnotetext{
${ }^{3}$ El papel de la política fiscal en la crisis de la convertibilidad se examina y discute, por ejemplo, en Damill, Frenkel y Juvenal (2003) y en Damill, Frenkel y Rapetti (2005).
} 
actividad disponibles). El detonante de la recuperación fue precisamente el cambio brusco de precios relativos a favor de los sectores productores de bienes comerciables. En un comienzo el impulso provino de la sustitución de bienes importados por bienes de producción interna.

Es destacable que el inicio de la nueva fase comenzara a hacerse perceptible cuando el país estaba todavía envuelto en un panorama de acentuada inestabilidad económica y de marcada incertidumbre política, y se encontraran interrumpidos los pagos del servicio de parte de la deuda pública. ${ }^{4}$ En otros términos, el "rebote" tomó cuerpo a pesar de ese cuadro inicial extremadamente complicado y de los efectos negativos que la depreciación cambiaria tuvo en diversos planos.

Más allá del cambio de precios relativos, el mérito de la rápida recuperación económica que siguió a la crisis se debe también a un conjunto de políticas que, aun con errores, marchas y contramarchas, apuntaron generalmente a recuperar los equilibrios macroeconómicos básicos. Es destacable el hecho de que varias de las políticas que desempeñaron papeles muy importantes en esta etapa debieron enfrentar la oposición del FMI. Cabe mencionar entre ellas la reimplantación de controles cambiarios (los que forzaron a los exportadores a liquidar en el mercado local buena parte de las divisas generadas por el comercio internacional y limitaron las salidas de fondos por cuenta de capital); el establecimiento de impuestos a la exportación (retenciones), que captaron para el fisco una parte del efecto favorable de la devaluación sobre los ingresos de los productores de bienes comerciables (contribuyendo grandemente a la recomposición del equilibrio fiscal), $\mathrm{y}$ atenuaron el impacto sobre los precios internos y, por ende, sobre las remuneraciones reales; una política monetaria flexible que permitió, por una parte, ayudar a los bancos en la fase de crisis y, luego, alimentar la recomposición de la demanda de dinero, apuntalando la recuperación; y una política cambiaria que procuró evitar la apreciación del peso mediante la intervención del Banco Central (y luego también del Tesoro Nacional, con recursos fiscales) cuando el mercado de divisas comenzó a presentar un exceso de oferta.

El FMI insistió en la libre flotación del peso y el gobierno adoptó este régimen por un breve lapso. Una

\footnotetext{
${ }^{4}$ El tipo de cambio subía aceleradamente luego de que se pasara, poco después de la devaluación inicial que había llevado la paridad a 1,40 pesos por dólar, a un régimen de flotación; las subidas de la paridad arrastraban a los precios nominales y el sistema financiero atravesaba una profunda crisis.
}

vez instaurada la flotación, el tipo de cambio se disparó, alcanzando niveles próximos a cuatro pesos por dólar, en un marco de expectativas de alzas mucho mayores. La reimplantación de los controles cambiarios fue esencial para contener la burbuja cambiaria. Forzando a los exportadores a liquidar divisas internamente, y limitando las salidas de fondos, el gobierno consiguió, hacia mediados de 2002, estabilizar el tipo de cambio nominal.

Rápidamente, en cuanto se hizo perceptible que esa situación podía persistir, la demanda de pesos comenzó a recomponerse y el mercado de divisas mostró un exceso de oferta. La interrupción de la burbuja en el mercado de cambios contribuyó decisivamente a contener las alzas de precios. En el mismo sentido operaron, por un lado, el congelamiento de las tarifas de los servicios de utilidad pública ${ }^{5} \mathrm{y}$, por otro, las elevadísimas tasas de desempleo, que mantuvieron contenidos a los salarios nominales en el sector privado. Todos estos fenómenos hicieron posible un rápido descenso de las tasas inflacionarias ya desde la segunda mitad de 2002.

\section{b) Las principales características de la fase de recuperación \\ El repunte del PIB iniciado en la primera mitad de} 2002 tuvo una breve fase inicial en la que la demanda global apenas aumentó, y todos los componentes del gasto interno (consumo privado, consumo público, inversión) siguieron contrayéndose, como habían hecho sostenidamente a lo largo de la depresión anterior, aunque a un ritmo menor. De modo que no fue el gasto interno lo que detuvo la declinación del nivel de actividad. Los factores que actuaron expansivamente fueron sobre todo las variables de comercio internacional: las exportaciones y las importaciones, en especial estas últimas. La demanda comenzó a ser abastecida en mayor medida por bienes producidos internamente, $y$ esta sustitución de importaciones benefició en particular al sector manufacturero. Sin embargo, luego de una corta etapa inicial, la fuente del dinamismo económico se desplazó claramente hacia los componentes de la demanda interna, particularmente a la inversión (que creció a un ritmo anualizado cercano al 40\% entre 2002 y 2004) y también hacia el consumo privado.

Es frecuente que se haga referencia al favorable entorno externo como uno de los elementos

\footnotetext{
${ }^{5}$ Muchas de las cuales estaban dolarizadas y se ajustaban por la inflación de los Estados Unidos, según rezaban los contratos establecidos al llevarse a cabo las privatizaciones.
} 
importantes detrás de la recuperación económica. En algunos análisis se suele atribuir a un conjunto de factores positivos "exógenos" el grueso de la explicación del repunte. Este, según tales estudios, se estaría dando pese a lo que, desde esa perspectiva, se interpreta como una política económica plagada de errores: falta de plan, excesivo intervencionismo, empleo de instrumentos inadecuados (como impuestos que causan distorsiones), demoras en la implementación de "reformas pendientes", y otros. Si bien el impacto de factores externos (en particular de los altos precios de algunos commodities) ha sido indudable, al menos hasta hace poco, el hecho de que el dinamismo de la expansión se deba sustancialmente a los factores de demanda interna quita sustancia a esa interpretación.
Cabe resaltar, asimismo, que la recuperación del consumo y la inversión se produjo en el contexto de un marcado racionamiento del crédito, tanto externo como interno. La inversión estuvo aparentemente alimentada por mayores ganancias retenidas por empresas y productores, aunque seguramente contribuyó también el "efecto riqueza" derivado de las importantes tenencias de activos externos por el sector privado residente. Estos activos, que hoy se ubican alrededor de los 125.000 millones de dólares, se valorizaron con la depreciación cambiaria, medidos en pesos o en comparación con activos internos como bienes inmuebles y tierras. Este mismo factor fue seguramente uno de los que alimentaron la recuperación del gasto privado de consumo.

\section{III}

\section{Los efectos de la evolución macroeconómica sobre el empleo y las remuneraciones}

\section{Las consecuencias de los procesos de apertura con apreciación cambiaria}

Los rasgos de la evolución macroeconómica argentina que hemos descrito han tenido su correlato en el mercado laboral. Los logros iniciales del programa de estabilización y reformas del decenio de 1990 —en materia de mayores niveles de actividad y menores tasas de inflación - tuvieron efectos positivos. Por un lado, una mayor actividad implicó más demanda de trabajo. Por otro, el descenso de la inflación tuvo un efecto favorable sobre el poder adquisitivo de los salarios. En términos más generales, dicho descenso disminuyó la magnitud del "impuesto inflación", que recae principalmente sobre los ingresos más bajos.

Estas consecuencias son características de programas de esa índole, en su fase inicial. Pero otros de sus efectos suelen tener signo negativo. Las privatizaciones suelen ir seguidas o precedidas de procesos de racionalización de las empresas que significan importantes reducciones de personal. Incidencia análoga tienen los ajustes del gasto de las administraciones públicas nacionales, provinciales y municipales, que habitualmente implican reducción de empleo y salarios. Tales efectos negativos sobre el empleo y los salarios se producen "por una vez".
Los efectos conjuntos de la apertura comercial y la apreciación cambiaria merecen, entre tanto, especial consideración, pues acarrean consecuencias adversas persistentes sobre el empleo en la producción de bienes comerciables, particularmente en la industria manufacturera.

La política de reducción de la protección arancelaria y no arancelaria persigue incrementar la eficiencia y la productividad del sector comerciable. Esto se busca a través de una mayor competencia en el mercado interno de los bienes importados y mediante el acceso de las empresas locales a insumos y bienes de capital de mejor calidad y menor precio. En todo caso, la apertura comercial implica el desplazamiento de empresas y empleo en las áreas menos eficientes del sector comerciable. En una versión simple de la teoría, esos efectos negativos deberían ser compensados por la creación simultánea de empleo en actividades que se hacen más competitivas merced a aumentos de la productividad. En versiones más complejas, se reconoce que puede haber un período más o menos largo de caída del empleo y efectos distributivos adversos, que deberían paliarse con políticas públicas. Más allá de ello, el hecho es que en Argentina, así como en otros países de América Latina en el decenio de 1990, la apertura comercial se dio conjuntamente con 
la apreciación de los tipos de cambio. ${ }^{6}$ Este factor acentuó la pérdida de competitividad de las industrias existentes e inhibió el surgimiento de nuevas actividades de exportación o sustitución de importaciones, agudizando los efectos adversos sobre el empleo.

Todos los efectos mencionados, positivos y negativos, se observaron en mayor o menor grado en Argentina y en otras economías de la región durante la década de 1990. El grado en que se dieron determinó el signo y la magnitud del impacto agregado en cada caso. La evolución en el tiempo del empleo y la distribución del ingreso dependió también de los diferentes ritmos de los procesos en cuestión. Un caso muy significativo, por la importancia relativa de los países involucrados, es el de la dinámica generada por estabilizaciones de shock con ancla cambiaria que incluyen más o menos simultáneamente la apertura comercial, las privatizaciones y el ajuste fiscal. En congruencia con la dinámica macroeconómica de carácter cíclico ya descrita, suele observarse también un ciclo en el comportamiento del empleo y los ingresos más bajos, con una primera fase, ascendente, en la que predominan los efectos positivos de la reactivación y la caída de la inflación, y una segunda fase, descendente, en la que los efectos iniciales tienden a atenuarse y predominan en particular las consecuencias persistentes de la conjunción de la apertura comercial y la apreciación cambiaria.

El ciclo de empleo que mencionamos se observa claramente en el caso argentino. Como veremos en detalle en el apartado siguiente, la tasa de empleo agregada tendió a crecer entre el lanzamiento del programa de convertibilidad (1991) y 1993, para descender continuadamente desde entonces y ubicarse a fines de 1996 bien por debajo de la tasa de empleo de 1990. La contracción afectó principalmente las ocupaciones de más de 35 horas semanales de hombres y jefes de hogar, y se concentró en los puestos de trabajo en la industria manufacturera. Si bien las privatizaciones y el ajuste fiscal de las provincias tuvieron efectos negativos sobre el empleo, el impacto desfavorable de más peso provino de la reestructuración y concentración de las actividades productoras de bienes

\footnotetext{
${ }^{6}$ Estas circunstancias contradicen las propias recomendaciones convencionales acerca de las políticas macroeconómicas que deben acompañar la apertura comercial. La mayor apertura implica menor protección de las actividades locales. En consecuencia, dado el tipo de cambio real, induciría el aumento del déficit comercial. Para eliminar este efecto indeseado, la teoría convencional de la apertura comercial recomienda acompañarla con una depreciación real.
}

comerciables, inducidas por la apertura comercial y la apreciación cambiaria.

La importancia de los efectos de la apertura con apreciación cambiaria hace al tema merecedor de un mayor desarrollo. El comportamiento de la demanda de trabajo derivada de la producción industrial puede desagregarse en tres componentes. En primer lugar se halla el componente positivo que resulta del crecimiento de la demanda global (demanda interna más exportaciones). Cuanto mayor es el aumento de la demanda, mayor será su efecto sobre la producción industrial y sobre el empleo en el sector. En segundo lugar, dado el crecimiento de la demanda global, existe un efecto negativo sobre la producción y el empleo derivado del grado de penetración de las importaciones que atienden esa demanda. Mientras mayor sea la proporción de la demanda atendida por las importaciones, menores serán la producción local y el empleo. En tercer lugar, la necesidad de ganar competitividad con rapidez en un contexto de apertura, por una parte, y el cambio de precios relativos a favor de los insumos y la maquinaria importados, por otra, inducen en las firmas una significativa reducción de mano de obra por unidad de producción. Este aumento de la productividad laboral resulta de cambios en la composición de la producción (por ejemplo, menor diversidad de productos con mayor componente de insumos importados), ganancias de eficiencia por reorganización y sustitución de mano de obra por maquinaria.

Como ya se mencionó, esos procesos han desembocado generalmente en una tendencia a la contracción del empleo en la industria. Esto es, el crecimiento de la demanda de bienes industriales ha sido insuficiente para compensar los componentes negativos, es decir, el desplazamiento directo de la producción local por importaciones y el proceso de reducción de trabajo local por unidad de producción que tiene lugar en las empresas sobrevivientes. Cabe mencionar que son las empresas medianas y pequeñas las que encuentran mayores dificultades para mantenerse en actividad, por lo cual el cierre de este tipo de firmas es un aspecto significativo de la contracción del empleo.

Merece ponerse de relieve el papel que desempeña la apreciación del tipo de cambio en cada uno de los componentes que hemos desagregado más arriba. Considérese la tasa de crecimiento de la demanda de bienes industriales. El tipo de cambio apreciado opera como factor restrictivo porque inhibe la tasa de crecimiento de las exportaciones y también limita la tasa de crecimiento de la demanda interna. En la trayectoria de largo plazo del crecimiento de la economía, la 
fragilidad externa asociada a la apreciación cambiaria constituye un factor que restringe la tasa de crecimiento potencial.

Es claro también el rol negativo de la apreciación cambiaria a través del segundo de los componentes mencionados arriba. La apreciación se suma a la apertura comercial para reducir adicionalmente la competitividad de las actividades locales. En consecuencia, dado el nivel de la demanda global, tiende a incrementar los efectos de desplazamiento directo de la producción y el empleo locales por importaciones. Asimismo, inhibe actividades de producción industrial para el mercado interno o para exportar que, aun en situación de economía abierta, resultarían competitivas con un tipo de cambio más depreciado.

Por último, el efecto adverso de la apreciación cambiaria sobre el empleo también es significativo a través del tercer canal: el proceso microeconómico de reducción de mano de obra por unidad de producción. El tipo de cambio apreciado exagera los incentivos para reducir la mano de obra por unidad de producción dentro de las empresas, pues baja adicionalmente el precio relativo de los insumos y la maquinaria importada respecto del costo de la mano de obra.

Podemos resumir en tres rasgos la configuración macroeconómica que tiende a configurarse en el proceso de apertura con apreciación cambiaria. Estos son la fragilidad del crecimiento, el alto desempleo y la tendencia a una creciente desigualdad en la distribución de los ingresos. La fragilidad externa implica la dificultad de sostener tasas de crecimiento elevadas sin enfrentar el riesgo de crisis externas, y fuerza a la economía a evolucionar sobre una trayectoria de bajo crecimiento, que de por sí inhibe la capacidad de creación de empleo. Tras la fragilidad externa está la baja competitividad internacional de las actividades locales. En Argentina, la competitividad agregada no tendió a aumentar en el decenio de 1990 pese a importantes mejoras de productividad de la mano de obra, porque la variación de los precios relativos neutralizó los efectos de esa mayor productividad. ${ }^{7}$ La tercera característica es principalmente consecuencia de las dos primeras. El desempleo alto, por sí mismo y por la presión a la baja que ejerce sobre los salarios, determina una persistente tendencia a una mayor desigualdad en la distribución de los ingresos.

\footnotetext{
7 Véase cómputos con metodología común para varios países en Tokman y Martínez (1999).
}

\section{Empleo, subempleo y desempleo en la Argentina del decenio de 1990}

En este apartado se presenta evidencia empírica relativa a la evolución de las condiciones del mercado de trabajo argentino que se ha descrito. Se comienza por examinar la evolución del empleo, el subempleo y el desempleo agregados en la década indicada.

Las series que se examinarán a continuación se refieren a la población urbana y provienen de la Encuesta Permanente de Hogares (EPH) que el Instituto Nacional de Estadística y Censos (INDEC) realizaba dos veces por año, en los meses de mayo y octubre. ${ }^{8}$

A menos que se señale lo contrario, las series que se analizan aquí están definidas como porcentajes de la población urbana total. Ellas son:

$$
\begin{aligned}
\text { PART }= & \text { tasa de participación; } \\
\text { EMPL }= & \text { tasa de empleo; } \\
\text { FTEMPL = } & \text { tasa de empleo de tiempo completo }{ }^{9} \\
\text { SUB }= & \text { tasa de subocupación involuntaria (o de sub- } \\
& \text { empleo); } \\
\mathrm{U} & =\text { tasa de desempleo. }
\end{aligned}
$$

El gráfico 4 muestra la evolución de esas variables desde comienzos de la década de 1980. En primer lugar, se observa que la tasa de empleo de tiempo completo sigue una tendencia marcadamente declinante, pasando de un 35\%-36\% en los primeros años de esa década a $32 \%$ en el primer semestre de 1990 y a $27,6 \%$ en el segundo semestre de $2001 .^{10}$

Además de esa tendencia negativa, la FTEMPL también presenta una clara correlación con el ciclo macroeconómico. Tal como sucede con el producto interno bruto (PIB), esta variable describe dos nítidos ciclos en el decenio de 1990. Se incrementa a partir de 1990, luego presenta una pronunciada caída que alcanza un

\footnotetext{
${ }^{8}$ Recientemente se ha modificado la metodología y la periodicidad de la EPH, según se describe más adelante.

${ }^{9}$ En la encuesta se considera que un individuo es un ocupado de tiempo completo si trabaja al menos 35 horas semanales. Se incluye también en este grupo a todo aquel que, habiendo trabajado menos de 35 horas, no quiere trabajar más (es decir, esta variable comprende al "subempleo voluntario").

${ }_{10} \mathrm{Tal}$ como se hace en el gráfico 4, adoptamos en este apartado una periodización semestral. Así, atribuimos al primer semestre la observación de la encuesta de hogares correspondiente a mayo de cada año, y al segundo semestre la observación de octubre, de manera que la notación 2000:1, por ejemplo, refiere al primer semestre del 2000. Por otro lado, en la mayor parte de los casos, en este apartado el signo \% indica que se trata de "puntos porcentuales de la población". Sin embargo, de aquí en adelante, cuando pueda presentarse ambigüedad, se utilizará la expresión "puntos porcentuales de la población" para hacer referencia a medidas de esa naturaleza.
} 
GRÁFICO 4

Argentina: Indicadores del mercado de trabajo ${ }^{a}$

(En porcentajes de la población urbana total)

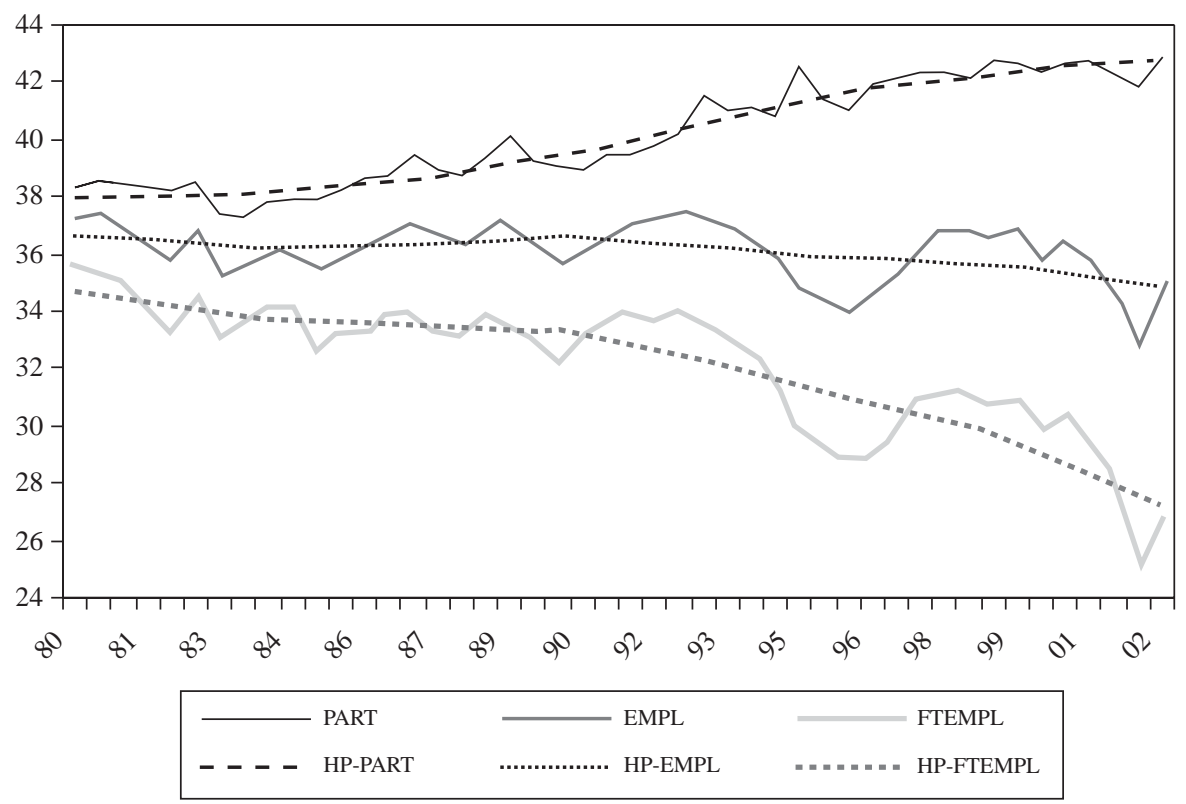

Fuente: Encuesta Permanente de Hogares del INDEC.

a Tasa de participación (PART), tasa de ocupación (EMPL); tasa de ocupación a tiempo completo (FTEMPL), y sus respectivas tendencias Hodrick-Prescott (HP-FTEMPL).

mínimo en 1996, para ascender nuevamente con la segunda expansión de la década y posteriormente contraerse una vez más desde 1998.

Sin embargo, es importante destacar que el máximo alcanzado por la FTEMPL en el período expansivo de los años tempranos del decenio de 1990 se registró en el segundo semestre de 1992 o bien antes del punto de inflexión del PIB (observado al cierre de 1994, luego de la crisis de México). Así, en 1993 y 1994, cuando la economía estaba todavía expandiéndose a un ritmo notable, el cociente entre los empleos de tiempo completo y la población total estaba ya declinando.

Entre aquel punto máximo (de 34,14\%) y el mínimo observado en el segundo semestre de 1996, la FTEMPL cayó aproximadamente 5,2\%. Se recuperó luego en alrededor de $2,4 \%$, alcanzando una nueva cima en el primer trimestre de 1998. Nótese, sin embargo, que ese valor es bien inferior al máximo alcanzado en la expansión previa.

La declinación subsiguiente acompañó la tendencia recesiva, tanto en el período de contracción moderada, hasta mediados de 2001, como en la fuerte caída de la actividad que tuvo lugar en el segundo semestre de 2001. Hacia el final del régimen de convertibilidad, en ese semestre, la FTEMPL se encontraba $6 \%$ por debajo del nivel que tenía en el primer semestre de 1991.

El cociente entre el empleo total y la población (EMPL) presentó también una tendencia declinante a comienzos del decenio de 1990; pero esta fue considerablemente menos pronunciada que en el caso de la FTEMPL, lo que indica que la tasa de subocupación (o de subempleo involuntario, sUB) tendió a incrementarse en ese mismo lapso. El aumento de la sub se acentuó en 1999-2000.

Además, como veremos enseguida, la suB presenta un comportamiento contracíclico, es decir, tiende a subir cuando la FTEMPL cae y a incrementarse cuando esta desciende. Como consecuencia, la EMPL tiene una vinculación más débil con el ciclo económico que la FTEMPL.

Finalmente, la tasa de participación de la población en la fuerza de trabajo (PART) presenta una tendencia marcadamente positiva que no se correlaciona con el ciclo macroeconómico. Partiendo de alrededor de $38 \%$ en 1980 , pasó a $39 \%$ en 1990 y saltó nuevamente, alcanzando el $42,8 \%$ en el primer semestre del 
GRÁFICO 5

Argentina: Tasas de desocupación (U) y de subocupación involuntaria (SUB)

(En porcentaje de la población activa urbana)

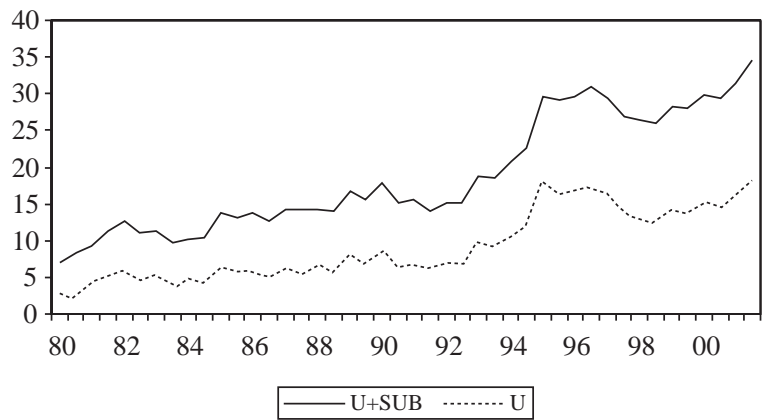

Fuente: Encuesta Permanente de Hogares del INDEC.

2001. A lo largo de todo el período de la convertibilidad, la tendencia de la PART correspondió a un incremento de aproximadamente un punto porcentual de la población urbana cada tres años. La principal razón de ese comportamiento ha sido el sostenido aumento de la participación femenina en la fuerza laboral. Dicha participación es todavía baja en Argentina si se la compara con estándares internacionales.

Como resultado de la tendencia positiva de la PART y del relativo estancamiento de la tasa de ocupación, la tasa de desempleo (U) se incrementó abruptamente en la década de 1990, con un marcado salto en el período 1992-1995 (gráfico 5).

El impacto de la crisis de 2001-2002 produjo un nuevo salto desfavorable de estos indicadores. La tasa de desempleo abierto urbano trepó hasta un máximo de $21,5 \%$ en mayo de 2002, para comenzar a descender desde entonces. La subocupación, entre tanto, alcanzó un máximo de 19,9\% de la población económicamente activa en octubre de 2002, y declinó también posteriormente, cuando la recuperación económica comenzó a tomar fuerza.

\section{La evolución del empleo y el desempleo en la fase reciente de recuperación}

\section{a) La evolución del empleo de tiempo completo}

En 2002, al calor de la reactivación económica, el empleo comenzó a recuperarse. En este apartado ${ }^{11}$

\footnotetext{
11 Tanto el análisis de la evolución reciente del empleo y el desempleo que se presenta en este apartado como el de los salarios (que se hace más adelante), se basan en Damill y Frenkel (2003) y Frenkel (2005).
}

se analiza primeramente la evolución del empleo de tiempo completo desde el segundo semestre de 2002. Nos interesa contar con una perspectiva de largo plazo, que permita analizar cambios en el tiempo y hacer comparaciones con el período del régimen de convertibilidad. Una dificultad para esto es que la EPH semestral se descontinuó el primer semestre de 2003 para ser sustituida por una EPH continua, que ofrece datos trimestrales. Se dispone de los resultados de la EPH continua por trimestres desde el primer trimestre del 2003, pero las tasas de empleo de ambas encuestas no son directamente comparables por los cambios de metodología.

Para resolver estos problemas se procedió del siguiente modo. Se calcularon promedios semestrales de las tasas de empleo de la EPH continua, de modo de contar con datos semestrales, de frecuencia similar a los provistos por la EPH semestral en el pasado. Además, en lugar de trabajar con los niveles de la tasa de empleo, se calculó una serie larga de diferencias semestrales (la diferencia entre un semestre y el precedente). El empalme de las series de diferencias entre semestres de las encuestas semestrales y de las encuestas continuas se realizó aprovechando que para el primer semestre de 2003 se cuenta con observaciones realizadas con ambas encuestas. Esto permite calcular todas las diferencias con datos semestrales de una misma EPH: la semestral hasta el primer semestre de 2003 y la continua desde el segundo semestre de ese mismo año. Si bien las diferencias semestrales así calculadas no son estrictamente homogéneas, cabe suponer que el error que se comete con este procedimiento es de poca monta.

Denominamos D(FTEMPL) a la variable que nos interesa. Esta es la variación entre un semestre y el precedente de la tasa de empleo de tiempo completo sin planes sociales. La exclusión de los planes sociales en la medición de FTEMPL es importante, porque la introducción del Plan Jefas y Jefes de Hogar trajo consigo un importante incremento en la tasa de subocupación voluntaria. ${ }^{12}$ Si la tasa de empleo de tiempo completo no excluyera los planes sociales, se observaría un incremento de ella no relacionado con los procesos económicos. De modo que la tasa de empleo de tiempo completo que consideramos excluye a los

\footnotetext{
${ }^{12}$ Nos referimos al Plan Jefas y Jefes de Hogar desocupados creado en 2002 para paliar la grave situación social generada por la agudización de la crisis y en virtud del cual se entregan subsidios de 150 pesos a jefes de hogares con hijos, a cambio de determinadas contraprestaciones.
} 
trabajadores con planes sociales. La variable D(FTEMPL) está medida en puntos porcentuales de la población urbana total. A continuación se muestra la evolución de esta variable desde el segundo semestre de 2002 hasta el primero de 2004, junto a las tasas de crecimiento semestral del PIB desestacionalizado que hemos denominado DL(PIB).

CUADRO 3

Argentina: Variación de la tasa de empleo de tiempo completo entre un semestre y el anterior, sin planes sociales

\begin{tabular}{lcc}
\hline Semestre & D(FTEMPL) & DL(PIB)*100 \\
\hline $2002: 2$ & 0,68 & 1,32 \\
$2003: 1$ & 1,06 & 5,07 \\
$2003: 2$ & 1,86 & 5,32 \\
$2004: 1$ & 0,96 & 3,37 \\
\hline
\end{tabular}

Fuente: Elaboración propia.

El cuadro 3 muestra que en los cuatro semestres considerados el PIB acumuló un crecimiento de 15,9\%, mientras que la tasa de empleo de tiempo completo se incrementó en 4,56 puntos porcentuales de la población urbana.

\section{b) El empleo de tiempo completo y el comportamiento} reciente del desempleo

En el año 2003 y el primer semestre del 2004 los incrementos del empleo de tiempo completo (sin planes sociales) explicaron totalmente las caídas observadas en las tasas de desempleo. Así se ve en el cuadro 4, que muestra las variaciones semestrales del desempleo y del empleo a tiempo completo. Para facilitar la comparación, las variaciones del desempleo D(U) están expresadas en porcentajes de la población urbana total.

CUADRO 4

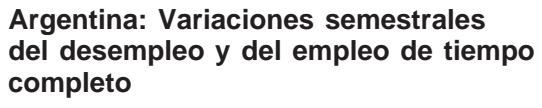

Argentina: Variaciones semestrales del desempleo y del empleo de tiempo completo

\begin{tabular}{lcc}
\hline Semestre & D(U) & D(FTEMPL) \\
\hline $2003: 1$ & $-0,94$ & 1,06 \\
$2003: 2$ & $-1,08$ & 1,86 \\
$2004: 1$ & $-0,35$ & 0,96 \\
\hline
\end{tabular}

Fuente: Elaboración propia.

En todos los semestres, los incrementos de la tasa de empleo de tiempo completo sin planes sociales superaron a las caídas semestrales del desempleo en valor absoluto.
En resumen, desde el 2003 las contracciones observadas del desempleo se explican por los incrementos de la tasa de empleo de tiempo completo sin planes sociales; tales planes han estado presentes en este escenario a modo de telón de fondo relativamente estable en el período. En consecuencia, los cambios de las condiciones en el mercado de trabajo a partir del año indicado pueden representarse por las variaciones de las tasas de desempleo y también por las variaciones de las tasas de empleo de tiempo completo.

\section{Un modelo agregado del mercado de trabajo}

Estos hechos estilizados relativos a los indicadores de utilización de la mano de obra pueden organizarse en un modelo simple del mercado de trabajo, con un nivel de empleo determinado por la demanda y los precios relativos, una función de subempleo que refleja el comportamiento contracíclico de esta variable y una tasa de participación exógena (que sigue una tendencia positiva, como se ha mencionado). Así, la tasa de desempleo se obtiene como la diferencia entre la tasa exógena de participación y la tasa de empleo, determinada por la demanda.

El comportamiento de la ocupación está asociado con la tendencia de la actividad económica. Sin embargo, la evolución del empleo total (según lo define la EPH), aun estando relacionada con el PIB, no muestra una correlación estrecha con esa variable indicativa del nivel de actividad. La causa principal de esa débil correlación es el comportamiento dinámico de uno de los componentes del agregado de empleo: el subempleo involuntario. En efecto, este tiene un comportamiento dinámico contracíclico, al igual que el desempleo. En cambio, la ocupación de tiempo completo es marcadamente procíclica en el corto plazo. En suma, el subempleo involuntario evoluciona en el corto plazo en una dirección opuesta a la del empleo de tiempo completo, de modo que el agregado empleo total varía en forma más atenuada y con mayor "ruido" que el empleo de tiempo completo.

El nivel de actividad no es el único determinante de la demanda agregada de trabajo. Otros factores afectan el crecimiento o contracción del empleo: por ejemplo, los precios relativos. Como en el caso del nivel de actividad, la incidencia de otros factores macroeconómicos determinantes de la demanda de

\footnotetext{
${ }^{13}$ Véanse versiones más detalladas de este modelo, así como estimaciones econométricas de él, en Frenkel y González Rozada (2000a y 2000b) y Damill, Frenkel y Maurizio (2002).
} 
trabajo también puede observarse con mayor nitidez a través de sus efectos sobre el empleo de tiempo completo. Ésta es la variable agregada del mercado de trabajo que mejor describe la articulación de dicho mercado con los procesos macroeconómicos. En consecuencia, para analizar esa articulación es conveniente proceder en dos pasos: examinar en primer lugar los factores que determinan el empleo de tiempo completo y, en segundo lugar, modelar el comportamiento del empleo total en función del empleo de tiempo completo y otras variables.

La reseña de las principales variables ocupacionales en Argentina que hicimos en el apartado anterior revela que la demanda de trabajo, representada principalmente por la variable FTEMPL, experimentó un profundo cambio en el decenio de 1990. Si bien el cociente entre las ocupaciones de tiempo completo y la población venía cayendo desde la década de 1980, fue la de 1990 la que se caracterizó por una perceptible agudización de esa tendencia.

En efecto, varios factores contribuyeron en esa década a un nítido cambio en la tecnología de producción y la organización de la actividad productiva de las empresas. La apertura comercial y la apreciación cambiaria se ubicaron indudablemente entre los más importantes.

Las modificaciones observadas en la demanda de bienes producidos internamente y en los precios relativos gravitaron en la utilización de trabajo por parte de las empresas. El gráfico 6 muestra el cociente entre la tasa de ocupación de tiempo completo y el PIB. Partiendo de una tendencia estancada en la década de 1980, la curva presenta una llamativa caída entre 1991 y 1996 y se estanca nuevamente con posterioridad.

GRÁFICO 6

Argentina: Cociente entre la tasa de ocupación de tiempo completo y el PIB, 1980-2000

(1990: $1=1)$

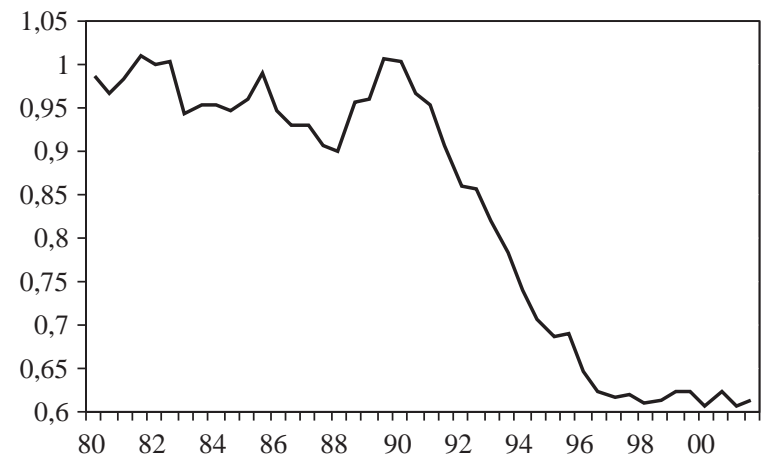

Fuente: Elaboración propia con datos del INDEC y del Ministerio de Economía y Producción.
Como hemos puntualizado ya, el nuevo esquema macroeconómico no emergió gradualmente. Las principales transformaciones institucionales y el cambio de precios relativos tuvieron lugar mayormente al comienzo del decenio de 1990. Teniendo en mente esa circunstancia, sugerimos que el ajuste de la demanda de trabajo puede concebirse como un proceso de adaptación, esta sí gradual, a un nuevo entorno definido desde un comienzo.

Para examinar la relación entre el crecimiento de la actividad y las variaciones de la tasa de empleo de tiempo completo estimamos el siguiente modelo:

$D($ FTEMPL $)=a$ DL $(P I B)+b$ DUMINIC $+d$ DUMRECU $+c+\varepsilon$,

donde $D(F T E M P L)$ y $D L(P I B)$ tienen los significados ya mencionados. $a, b, c$ y $d$ son parámetros por estimar y $\varepsilon$ es una variable aleatoria. El modelo dice que las variaciones semestrales de la tasa de empleo de tiempo completo resultan de un efecto de corto plazo del nivel de actividad y de una tendencia adicional, que puede concebirse como el ajuste lento de la tasa de empleo de tiempo completo a las condiciones del entorno (definidas principalmente, a comienzos del decenio de 1990, por la apreciación cambiaria y la apertura comercial).

La estimación de dicho modelo se hizo sobre series semestrales, con datos del período que va del primer semestre de 1991 al primer semestre del 2004 (cuadro 5).

Los resultados de la estimación por mínimos cuadrados ordinarios (MCO) se muestra en el cuadro 5.

DUMINIC es una variable ficticia, con valor 1 entre el primer semestre de 1991 y el primer semestre de 1996 y 0 en el resto del período, que es introducida para captar la magnitud y significación de la tendencia a la contracción del empleo de tiempo completo en el primer quinquenio del régimen de convertibilidad. ${ }^{14}$ DUMRECU es una variable ficticia con valor 1 entre el segundo semestre del 2002 y el primer semestre del 2004 y con valor 0 el resto del período, que capta la tendencia adicional en el período de recuperación reciente.

Los coeficientes son significativos al $3 \%$ y la constante no es significativa. El coeficiente de la tasa de variación del PIB es 0,19 . Un incremento de $10 \%$ del PIB aporta 1,9 puntos porcentuales de aumento de la tasa de empleo a tiempo completo. Además del efecto

14 Véase Damill, Frenkel y Maurizio (2002). 
CUADRO 5

\section{Argentina: Estimación del modelo de comportamiento del empleo de tiempo} completo por el método de mínimos cuadrados ordinarios

Variable dependiente: $\mathrm{D}(\mathrm{T})$

Muestra (ajustada): 1991:1 2004:1

Observaciones incluidas: 27 después de ajustar los puntos extremos

Errores estándares y covarianza consistentes con la heteroesquedasticidad de White

\begin{tabular}{l|c|r|r|r}
\hline Variable & Coeficiente & Error estándar & Estadístico t & Prob. \\
\hline DL(PIB)*100 & 0,19 & 0,03 & 6,36 & 0,000 \\
DUMINIC & $-0,64$ & 0,27 & $-2,35$ & 0,028 \\
DUMRECU & 0,62 & 0,26 & 2,35 & 0,028 \\
$\mathrm{C}$ & $-0,21$ & 0,18 & $-1,14$ & 0,260 \\
\hline $\mathrm{R}^{2}$ & 0,72 & \multicolumn{2}{|c}{ Estadístico f } & 19,27 \\
$\mathrm{R}^{2}$ ajustado & 0,68 & Prob. (estadístico f) & 0,000 \\
Estadístico Durbin-Watson & 2,54 & & & \\
\hline
\end{tabular}

Fuente: Elaboración propia con datos de la Encuesta Permanente de Hogares del Instituto Nacional de Estadística y Censos (INDEC) y del Ministerio de Economía y Producción.

de corto plazo de la variación del nivel de actividad, los coeficientes de DUMINIC $(-0,64)$ y DUMRECU $(0,62)$ describen las tendencias (de la tasa de empleo a tiempo completo) adicionales a las establecidas por la tasa de variación del PIB.

Esa tendencia adicional es negativa en la primera fase de la convertibilidad. Se trata de la tendencia autónoma a la caída del empleo de tiempo completo que puede interpretarse como resultante de la adaptación gradual al contexto de precios relativos del decenio de 1990. Por el contrario, la tendencia adicional resulta positiva en el período de recuperación reciente. ${ }^{15}$ En

\footnotetext{
${ }^{15}$ En Damill, Frenkel y Maurizio (2002) presentamos estimaciones econométricas de este modelo realizadas sobre el período 1980primer semestre del 2001, algunas de las cuales resumimos brevemente en esta nota.

Las ecuaciones allí estimadas para el decenio de 1990 asumen la forma: $d \log F T E M P L=\alpha d \log Y R+\lambda$ Dpost $96+\beta$, donde la variable dependiente no es la tasa de variación del número de ocupaciones de tiempo completo, sino la tasa de cambio de FTEMPL, que a su vez es igual a la tasa de variación del número de personas ocupadas a tiempo completo $(\operatorname{dlog} N)$ menos la tasa de crecimiento poblacional $(d \log P O B)$, lo que se expresa así: $\operatorname{dlog} F T E M P L=d \log N-d \log P O B$.

Por lo tanto, el coeficiente $\beta$ estimado refleja el efecto negativo conjunto, sobre FTEMPL, del ajuste del empleo al nuevo contexto, por una parte, y del crecimiento de la población, por otra.

La variable Dpost96 es una variable ficticia destinada a captar una modificación de la demanda de trabajo posterior a 1996. Esta variable asume un valor cero hasta el segundo semestre de 1996 y un valor igual a 1 para todos los semestres siguientes.

Las estimaciones econométricas de tales ecuaciones mostraron los siguientes resultados para el decenio de 1990. En primer lugar, la elasticidad $\alpha$ resultó positiva y significativamente distinta de cero. La estimación arrojó un valor de aproximadamente 0,6. Esta elas-
}

este último período corresponde a un crecimiento autónomo anual de la tasa de empleo de tiempo completo de algo más de 1,20 puntos porcentuales de la población urbana total.

En el período de recuperación reciente, el incremento semestral de la tasa de empleo de tiempo completo se explica bien con la ecuación:

$$
D(F T E M P L)=0,19 * D L(P I B) * 100+0,62
$$

(tomando en cuenta que DUMINIC $=0$ en este período). Por ejemplo, si el producto se incrementa $8 \%$ en un año, la variación de la tasa de empleo de tiempo completo se estima en aproximadamente $0,19 * 8+1,24=2,76$ puntos porcentuales.

ticidad implica que la tasa de empleo a tiempo completo tendía a crecer (caer) 1 punto porcentual por cada $6 \%$ de crecimiento (contracción) del PIB. La elasticidad-producto del empleo de tiempo completo en el decenio de 1990 resultó mayor que la correspondiente al decenio de 1980.

El parámetro $\beta$ estimado resultó también significativamente distinto de cero y negativo. La estimación cuantitativa implicó una tendencia a la contracción de la tasa de empleo a tiempo completo de 1,44 puntos porcentuales por año, en el período 1991-1996, que puede interpretarse como la tendencia autónoma a la caída del empleo de tiempo completo — siendo el producto constante- que resulta de la adaptación gradual al contexto de precios relativos de la década de 1990.

Otro resultado importante es el relativo a Dpost96. El coeficiente estimado de esta variable ficticia resultó positivo y de un valor absoluto muy semejante al del estimador de $\beta$. Esto significa que la tendencia contractiva autónoma $\beta$ se hizo nula en el período posterior a 1996 
Bajo el supuesto de estabilidad de la función, puede proyectarse la contribución del crecimiento del PIB (a través de la tasa de empleo de tiempo completo sin planes sociales) a la caída de la tasa de desempleo. Un incremento del PIB de $10 \%$ en determinado año daría lugar a que la tasa de empleo de tiempo completo aumentara en $0,19 * 10+1,24=3,14$ puntos porcentuales de la población urbana total. Considerando una tasa de actividad de $46 \%$, ese incremento de la tasa de empleo a tiempo completo equivaldría a casi 7 puntos porcentuales de la población activa.

Con el fin de completar la descripción de los indicadores agregados de utilización de la mano de obra, cabe considerar la evolución del subempleo involuntario. Ya hemos indicado que esa variable tiene un comportamiento contracíclico, de modo que se correlaciona negativamente con el empleo de tiempo completo. Nuestras estimaciones con datos de la década de 1990 indican que la tasa de subempleo involuntario tiende a caer (aumentar) 0,2 puntos porcentuales por cada punto porcentual de aumento (caída) de la tasa de empleo de tiempo completo. De modo que el aumento (caída) del empleo total resultante de un aumento (caída) del empleo de tiempo completo es menor que este último. Naturalmente, las variaciones del empleo total resultan de agregar las variaciones del empleo de tiempo completo y del subempleo involuntario.

\section{La contracción del empleo en el decenio de 1990 , por sectores productivos}

a) El empleo de tiempo completo por sector productivo

Acabamos de examinar los indicadores agregados de empleo generados a partir de la EPH nacional. La principal área urbana del país, que comprende la Ciudad de Buenos Aires y las jurisdicciones circundantes, configura el Gran Buenos Aires (GBA), que abarca alrededor de $37 \%$ de la población urbana total. En este apartado 5 nos basaremos en este subconjunto de la muestra —es decir, el GBA— para analizar la evolución del empleo en forma más desagregada.

Se ha argumentado más arriba que en la década de 1990 es posible identificar una clara tendencia a que se contraiga la relación entre las ocupaciones de tiempo completo y la población. El cuadro 6 presenta esa misma relación, por sectores de actividad, para el GBA. ${ }^{16}$ Las cifras incluyen el comienzo y el final del período de vigencia del régimen de convertibilidad, así como los máximos y mínimos dentro de él, y la diferencia entre ambos extremos del período (en la columna de la derecha).

Hemos indicado que la apertura comercial y la apreciación cambiaria contribuyeron al ajuste contractivo del empleo en el decenio de 1990, por su impacto negativo sobre los sectores que producen bienes

CUADRO 6

Argentina: Tasa de ocupación de tiempo completo por sector productivo

(En porcentaje de la población total del GBA; semestres seleccionados)

\begin{tabular}{|c|c|c|c|c|c|c|c|c|c|}
\hline & 1990:1 & 1992:2 & $1996: 2$ & 1998:1 & $2000: 2$ & 2001:1 & $2001: 2$ & $\begin{array}{c}\text { Diferencia } \\
\text { 2001:2- } \\
\text { 2001:1 }\end{array}$ & $\begin{array}{c}\text { Diferencia } \\
\text { 2001:2- } \\
1990: 1\end{array}$ \\
\hline Manufacturas & 8,54 & 8,76 & 6,33 & 6,69 & 5,55 & 5,20 & 4,66 & $-0,54$ & $-3,88$ \\
\hline Construcción & 1,91 & 2,30 & 1,81 & 2,17 & 1,89 & 1,60 & 1,22 & $-0,37$ & $-0,69$ \\
\hline Comercio & 6,60 & 7,17 & 6,22 & 6,15 & 6,55 & 6,00 & 5,79 & $-0,20$ & $-0,81$ \\
\hline Transp. y com. & 2,75 & 2,43 & 2,93 & 3,00 & 3,05 & 3,01 & 2,72 & $-0,29$ & $-0,03$ \\
\hline Otros servicios & 7,95 & 7,70 & 6,56 & 7,62 & 7,49 & 7,32 & 6,94 & $-0,38$ & $-1,01$ \\
\hline Total & 30,13 & 30,95 & 27,18 & 29,29 & 28,27 & 26,38 & 24,27 & $-2,11$ & $-5,86$ \\
\hline
\end{tabular}

Fuente: Elaboración propia con datos del INDEC.

\footnotetext{
${ }^{16}$ La definición del empleo de tiempo completo que se utiliza en este apartado es más restrictiva que la usada previamente, puesto que excluye a los subempleados voluntarios. Por otro lado, cabe señalar que las cifras del Gran Buenos Aires se asemejan estrecha-
}

mente a las nacionales. Por ejemplo, la variación de FTEMPL fue de $-1,86$ puntos porcentuales entre el primer semestre de 1990 y el segundo del 2000 para el Gran Buenos Aires (según se observa en el cuadro) y de $-1,8$ puntos porcentuales en el plano nacional. 
comerciables. En efecto, el cuadro 6 confirma que la considerable reducción de la tasa de empleo de tiempo completo en la industria manufacturera explica en gran medida el comportamiento agregado. Los otros dos sectores con una participación relevante en el número de ocupaciones de tiempo completo (comercio y otros servicios) presentan también cifras negativas, pero mucho menores. Más precisamente, en el período que va hasta el primer semestre de 2001, la contracción de los empleos de este tipo en las actividades industriales habría explicado por sí sola una reducción del número de puestos de trabajo de tiempo completo equivalente a la contracción total del empleo de tiempo completo. El colapso de la actividad en el segundo semestre de 2001 indujo, en cambio, una contracción de distribución sectorial más uniforme, lo que tendió a reducir un poco la participación de las manufacturas en la contracción total del empleo en la comparación entre el comienzo y el fin del período.

Por otra parte, si se examina la evolución de los puestos de trabajo de tiempo completo por categorías, se comprueba que perdieron terreno especialmente los trabajadores hombres y jefes de hogar, que son tradicionalmente predominantes en el sector manufacturero. ${ }^{17}$

Dado el peso decisivo de las manufacturas en la evolución de FTEMPL, cabe examinar más a fondo el empleo en este sector, lo que se hace a continuación.

\section{b) La ocupación en el sector industrial}

La Encuesta de Empresas Industriales que el INDEC publica mensualmente suministra información adicional sobre la industria manufacturera. Su alcance es nacional y comprende alrededor de 1.300 firmas con más de 10 trabajadores.

El gráfico 7 muestra las series de volumen físico de la producción, horas trabajadas y número de personas ocupadas a lo largo del decenio de 1990, según surgen de esa encuesta.

La evolución del empleo industrial puede explicarse con un modelo que se asemeja al que describe el comportamiento del empleo total de tiempo completo, presentado más arriba. ${ }^{18}$ En este caso estimamos específicamente el efecto de las nuevas condiciones de apertura y apreciación cambiaria sobre el empleo en la industria manufacturera, a partir de una función de

17 Véase Damill, Frenkel y Maurizio (2002 y 2003).

18 Véase Damill, Frenkel y Maurizio (2002 y 2003).
GRÁFICO 7

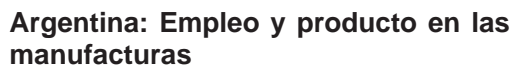

$(1993=100)$

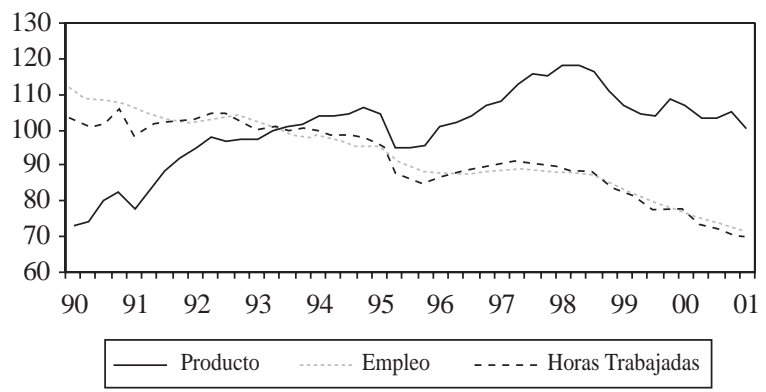

Fuente: INDEC.

demanda de empleo industrial que toma la siguiente forma:

$$
d \log \text { Nind }=\alpha d \log (P I B)+s
$$

donde Nind (ocupación en la industria) es definida alternativamente como el número de trabajadores empleados (Npers) o como el total de horas trabajadas (Nhoras); PIB representa el volumen físico de la producción, en tanto que $\alpha$ es la elasticidad empleo-producción y $s$ representa el ajuste gradual del empleo manufacturero a las condiciones vigentes desde el principio de la década de 1990.

Las estimaciones econométricas de ecuaciones de la forma indicada, realizadas con datos trimestrales para el período 1990:0-2001:1, arrojaron los resultados que se indican a continuación.

En primer lugar, la estimación de $s$ resultó significativa y de aproximadamente $-1 \%$ (trimestral), lo que implica una tendencia autónoma a la contracción del empleo industrial algo mayor al $4 \%$ anual. Esa tendencia contractiva es de valor absoluto mayor que la estimada para el empleo de tiempo completo total en el mismo período. Esto es congruente con la hipótesis que predice un mayor efecto contractivo en el sector de bienes comerciables.

En segundo lugar, a diferencia de lo observado en el empleo total de tiempo completo, la tendencia contractiva no desaparece en la segunda mitad de la década de 1990, sino que persiste hasta el final del período.

En tercer lugar, la estimación de la elasticidad empleo-producción industrial es significativa y positiva. Al igual que el empleo de tiempo completo total, la ocupación en la manufactura varía en el corto plazo 
según el nivel de actividad. Con el empleo medido en número de trabajadores ocupados se estiman elasticidades de entre 0,14 y 0,16 . Cuando se lo mide en número de horas trabajadas se estiman elasticidades de entre 0,55 y 0,59 .

La importante diferencia entre las elasticidades en las estimaciones con personas ocupadas y horas trabajadas indica una conducta de mantenimiento preventivo de personal (labor hoarding).

\section{La evolución de los ingresos medios en la década de 1990}

La generación de empleo y el comportamiento de la desocupación, que hemos examinado en esta sección III, son variables decisivas para entender la evolución de las remuneraciones obtenidas por el conjunto de la población. En el presente apartado nos ocuparemos inicialmente de la evolución de los ingresos medios de la población en el decenio de 1990, para enfocar luego su distribución. ${ }^{19}$

En el gráfico 8 se presenta la evolución del ingreso real medio por trabajador ocupado y por integrante de la población activa desde el primer semestre de 1991 hasta octubre de 2002. Ambas series siguen trayectorias procíclicas. En el período de expansión de comienzos de la década el ingreso medio de los trabajadores ocupados creció un 22\% (alcanzando su máximo en el primer semestre de 1994), mientras que el de la población activa aumentaba en $19 \%$. A partir de allí ambas series exhibieron declinaciones y alcanzaron mínimos locales en el segundo semestre de 1996. Comenzó entonces un segundo ciclo, cuya fase expansiva se extendió hasta el segundo semestre de 1998. Sin embargo, ninguna de las series recuperó el valor máximo precedente. Con posterioridad, los ingresos de trabajadores y activos declinaron en forma persistente hasta finales del período contemplado en el gráfico.

En octubre del 2001, antes del fin de la convertibilidad, el nivel del ingreso de los ocupados era $7 \%$ más alto que el vigente a comienzos de la serie, mientras que en el caso de los activos registraba una pérdida de $6 \%$, encontrándose ambos niveles claramente por debajo del máximo registrado en el primer semestre de 1994. Esto muestra que solo al principio de la década

${ }^{19}$ Las cifras de ingresos que aparecen en este apartado, así como los cuadros que caracterizan su distribución incluidos más adelante en el apartado 7, corresponden a datos de la EPH para el Gran Buenos Aires.
GRÁFICO 8
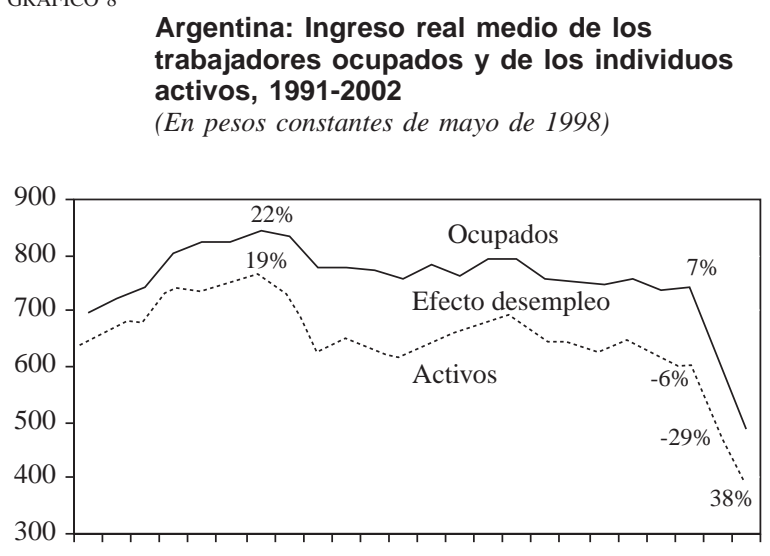

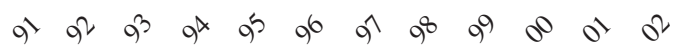

Fuente: Elaboración propia con datos del INDEC.

de 1990 se produjo un incremento importante en las remuneraciones reales, explicado fundamentalmente por la estabilidad de los precios y el crecimiento económico experimentado en esos años. Entre los extremos de la serie las remuneraciones disminuyeron en $30 \%$ en el caso de los ocupados y $38 \%$ en el de los activos.

La creciente brecha entre las dos series del gráfico 8 refleja el impacto del aumento de la tasa de desempleo en el Gran Buenos Aires a partir de 1993, y especialmente desde el primer semestre de 1995 en adelante. En ese momento el ingreso medio de la población activa sufrió una aguda contracción. La disminución del desempleo entre fines de 1996 y 1998 contribuyó a cierta reducción de la brecha, pero esta se revirtió en la fase de incremento sostenido de los índices de desocupación. Mientras que a comienzos del decenio de 1990 el ingreso medio de los activos equivalía al 93\% del obtenido por el conjunto de los trabajadores, hacia el final del lapso en estudio esa proporción había bajado a $82 \%$.

Estos hechos revisten suma importancia a la hora de explicar la tendencia de los ingresos que obtienen los hogares. El gráfico 9 muestra la dinámica del ingreso familiar per cápita.

En el gráfico 9 se observan fases de crecimiento y disminución similares a las señaladas anteriormente. El ingreso per cápita registró un incremento del $23 \%$ hasta el primer semestre de 1994, para luego caer fuertemente hasta el primer semestre de 1996. La recuperación parcial posterior se detuvo en 1998. Posteriormente, siguiendo la tendencia observada en los ingresos laborales, la serie experimentó una fuerte caída 
GRÁFICO 9

\section{Argentina: Ingreso medio real familiar per cápita \\ (En pesos constantes de mayo de 1998)}

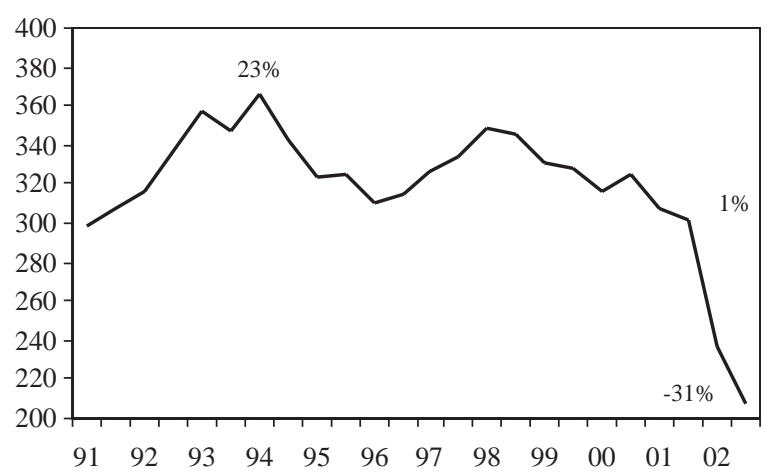

Fuente: Elaboración propia con datos del INDEC.

hasta el final del período. Luego del incremento de los primeros años, hacia el final del régimen de caja de conversión el ingreso medio había retornado a su nivel inicial. Por su parte, el rebrote inflacionario de comienzos del 2002 implicó una pérdida adicional de ingreso medio del orden del $30 \%$.

Se concluye, entonces, que el entorno macroeconómico desfavorable y su correlato en el escaso dinamismo del mercado de trabajo — con bajo nivel de demanda laboral, precariedad del empleo y crecientes niveles de desocupación - se tradujo en una fuerte caída de las remuneraciones a partir de 1994 , reforzada más tarde por el alza de los precios que siguió al abandono del régimen instaurado en 1991.

Cabe destacar, en particular, el papel del creciente nivel de desempleo sobre la generación de ingresos de los hogares. La fuerte caída del ingreso medio de la población activa entre los extremos del período estuvo determinada por el comportamiento de las remuneraciones de los ocupados y también por la evolución del nivel de desempleo. ${ }^{20}$ Este último tiene un impacto directo sobre la generación de ingresos de los activos, por cuanto la persona que se encuentra desocupada probablemente no registre ingreso alguno. Sin embargo, los altos niveles de desocupación a lo largo de toda la década tuvieron además un efecto negativo

20 Véase en Damill, Frenkel y Maurizio (2002 y 2003) un análisis detallado de la forma en que evolucionó la distribución del ingreso desde inicios de la década de 1990. Véase también Frenkel y González Rozada (2000b), Altimir y Beccaria (2000), y Beccaria y Maurizio (2001). importante, indirecto, sobre los salarios de la población efectivamente ocupada, lo que se reflejó en una elevada elasticidad negativa de las remuneraciones al desempleo, según se ve en la sección siguiente.

\section{Remuneraciones y desempleo}

En este apartado analizamos los ingresos de los trabajadores ocupados, considerando la gravitación del desempleo. La desocupación tiene un impacto directo y obvio sobre el ingreso medio de la población activa; pero también afecta a las remuneraciones de los ocupados. Varios esquemas teóricos, como el modelo insider-outsider de determinación de salarios, el argumento de "salarios de eficiencia" y la determinación del salario mediante la negociación entre sindicatos y empresas, pueden explicar la existencia de una elasticidad negativa de las remuneraciones reales al desempleo. Esta relación suele denominarse "curva de salarios" (wage curve), que a continuación estimamos esa relación para el mercado laboral argentino en el decenio de 1990.

\section{a) La curva de remuneraciones en el decenio de 1990}

Estimamos ecuaciones de remuneraciones utilizando microdatos extraídos de la EPH en el período que va del primer semestre de 1990 al segundo semestre de 1998, a partir de datos individuales relativos a 11 centros urbanos relevados por la EPH.

La ecuación de remuneraciones estimada asume la siguiente forma:

$$
\ln w=\partial\left(x, U_{r}, r, s, \text { DUMINIC }\right)
$$

donde $w$ designa el ingreso de los trabajadores en términos reales y $U r$ las tasas de desempleo en los diferentes centros urbanos, en logaritmos. Los términos $x$, $r$ y $s$ corresponden a variables de control, $x$ es un vector de características de los trabajadores (género, educación, tipo de ocupación y edad, y edad al cuadrado como variables sustitutivas de la rentabilidad de la experiencia); $r$ y $s$ son vectores de variables ficticias (regionales y por sector, respectivamente). El grupo de control está integrado por los asalariados de tiempo completo en el sector manufacturero, hombres, residentes en el Gran Buenos Aires y con educación primaria completa. Finalmente, DUMINIC es una variable ficticia cuyo valor es 1 entre el primer semestre de 1990 y el segundo semestre de 1992, y 0 desde 
entonces en adelante. La misma variable capta el efecto inicial del plan de convertibilidad sobre el ingreso real de los trabajadores.

Dado que las tasas de desempleo varían de una región a otra y a lo largo del tiempo, el coeficiente estimado para dicha tasa puede ser interpretado como la elasticidad-desempleo de las remuneraciones a lo largo del tiempo y por región.

El desempleo puede afectar a los ingresos totales a través de dos vías. Por una parte, reduce el número de horas trabajadas, y por otra, puede incidir negativamente en las remuneraciones horarias.

Así, hemos estimado la elasticidad-desempleo de estas últimas, y también del ingreso total. Además, estimamos una ecuación en la cual las horas trabajadas (en logaritmos) dependen de las mismas variables explicativas, con el propósito de distinguir el efecto de las remuneraciones horarias (efecto precio) que tienen las horas trabajadas (efecto cantidad) sobre el ingreso total. Realizamos estimaciones separadas para los asalariados de tiempo completo y para todos los ocupados. Encontramos que, si bien la tasa de desempleo gravita negativamente en las remuneraciones por hora en todos los casos, solo incide en el número de horas trabajadas cuando se trata de los trabajadores involuntariamente subocupados. Este efecto se verifica desde el primer semestre de 1993.

En el cuadro 7 se muestran las estimaciones de la elasticidad-desempleo de las remuneraciones horarias. Las correspondientes a las horas trabajadas y al ingreso total se presentan más adelante y solo para el grupo constituido por los subocupados involuntarios. ${ }^{21}$

La variable explicativa en la ecuación de remuneraciones fue definida alternativamente como la tasa de desempleo en sentido estricto o bien como la suma de esta última con la tasa de subocupación involuntaria (cuadro 8). En todas las estimaciones se empleó el método de mínimos cuadrados ordinarios. Los coeficientes estimados para las variables de control fueron muy significativos en la mayor parte de los casos y resultan muy similares a los obtenidos para la función estadística de ingresos estimada para todo el período. Los hemos omitido en los cuadros que siguen.

En todas las estimaciones los coeficientes de las variables explicativas son muy significativos y tienen

\footnotetext{
${ }^{21}$ Las elasticidades-desempleo de las remuneraciones reales obtenidas son muy similares a las estimadas para los Estados Unidos, por ejemplo. Para más detalles, véase Blanchflower y Oswald (1996).
}

CUADRO 7

\section{Argentina: Elasticidad-desempleo de las} remuneraciones reales por hora

\begin{tabular}{ccc}
\hline \multirow{2}{*}{ Variable } & \multicolumn{2}{c}{ Remuneraciones horarias } \\
\cline { 2 - 3 } & $\begin{array}{c}\text { Asalariados } \\
\text { de tiempo } \\
\text { completo }\end{array}$ & $\begin{array}{c}\text { Todos } \\
\text { los } \\
\text { ocupados }\end{array}$ \\
\hline Log(tasa de desempleo/100) & $\begin{array}{c}-0,095 \\
(-17,74)\end{array}$ & $\begin{array}{c}-0,102 \\
(-20,88)\end{array}$ \\
Duminic* $\log ($ tasa de desempleo/100) & 0,027 & 0,028 \\
& $(16,09)$ & $(18,41)$ \\
\hline
\end{tabular}

Fuente: Elaboración propia con datos de la Encuesta Permanente de Hogares del INDEC.

CUADRO 8

Argentina: Elasticidad de las remuneraciones reales por hora en relación con la suma de las tasas de desempleo y de subocupación

\begin{tabular}{llc}
\hline \multirow{2}{*}{ Variable } & \multicolumn{2}{c}{ Remuneraciones horarias } \\
\cline { 2 - 3 } & $\begin{array}{c}\text { Asalariados } \\
\text { de tiempo } \\
\text { completo }\end{array}$ & $\begin{array}{c}\text { Todos } \\
\text { los } \\
\text { ocupados }\end{array}$ \\
\hline Log(tasa de desempleo + suboc./100) & $\begin{array}{l}-0,133 \\
(-20,86)\end{array}$ & $\begin{array}{c}-0,150 \\
(-25,64)\end{array}$ \\
$\begin{array}{l}\text { Duminic*log(tasa de desempleo+ } \\
\text { subocupación/100) }\end{array}$ & 0,039 & 0,043 \\
& $(17,86)$ & $(21,17)$ \\
\hline
\end{tabular}

Fuente: Elaboración propia a partir de cifras de la Encuesta Permanente de Hogares del INDEC.

el signo esperado (en el cuadro, los estadísticos t aparecen entre paréntesis bajo el estimador). Por lo tanto, no se rechaza la hipótesis de una elasticidad-desempleo negativa del ingreso. Por otra parte, el coeficiente de la variable DUMINIC es significativo y positivo, lo que indica que la elasticidad remuneraciones-desempleo resultó menor al inicio del período, cuando el desempleo aún no estaba aumentando.

Las elasticidades estimadas son menores para los asalariados de tiempo completo que para el resto de los ocupados. Su valor alcanza a -0,095 para ellos, mientras que se eleva a $-0,102$ para el total de los trabajadores ocupados.

Esto indica que el grupo constituido por los no asalariados y los subocupados involuntarios enfrentó una flexibilidad algo mayor en sus remuneraciones. Mientras que un aumento de $10 \%$ de la tasa de desempleo dio lugar a una caída de $0,95 \%$ en las remuneraciones horarias de los asalariados de tiempo completo, la baja fue de 1,02\% para los ocupados en general. 
Nótese que la tasa de subocupación involuntaria tiene un efecto negativo adicional sobre el ingreso. Como se observa en el cuadro 8 , si se suma esa tasa al desempleo las elasticidades estimadas son de $-0,133$ para los asalariados de tiempo completo y de $-0,150$ para los ocupados en general, respectivamente.

Examinemos ahora las elasticidades estimadas para los subocupados involuntarios (cuadro 9). Las variables explicativas son las mismas, pero la variable DUMINIC fue suprimida debido al período considerado en este caso.

El cuadro 9 muestra que el aumento de la tasa de desempleo afectó a este grupo de manera negativa por dos vías: la reducción de las remuneraciones horarias, por una parte, y un descenso de la cantidad de horas trabajadas, por otra. Un aumento de $10 \%$ en la tasa de desempleo dio lugar a una contracción de $1,15 \%$ en los ingresos horarios, así como a una reducción de 1,35\% en la cantidad de horas trabajadas. En consecuencia, la baja del ingreso total de los subocupados involuntarios fue de $2,5 \%$.

Finalmente, estimamos la curva de remuneraciones para los asalariados de tiempo completo de manera separada para cada uno de los centros urbanos contemplados en la muestra, con el fin de establecer si las elasticidades estimadas reflejan primariamente el efecto de las variaciones del desempleo a través del tiempo, o el de las variaciones entre regiones. Las variables de control utilizadas fueron las mismas y los coeficientes estimados resultaron significativos en casi todos los casos. El cuadro 10 presenta las elasticidades estimadas para cada núcleo urbano.

Se comprueba en el cuadro 10 que las elasticidades-desempleo de las remuneraciones reales fueron negativas y significativas, salvo en Santa Cruz y Tucumán, lo que indica que los coeficientes estimados con anterioridad reflejan básicamente el efecto del desempleo a lo largo del tiempo. Las tasas de desempleo aumentaron marcadamente durante la década de 1990 en todos los centros urbanos. Cuando la ecuación

CUADRO 9

\section{Argentina: Elasticidad-desempleo de las remuneraciones reales y de las horas trabajadas de los subocupados}

\begin{tabular}{cccc}
\hline Variable & $\begin{array}{c}\text { Remuneraciones } \\
\text { horarias }\end{array}$ & $\begin{array}{c}\text { Horas } \\
\text { trabajadas }\end{array}$ & $\begin{array}{c}\text { Remuneración } \\
\text { total }\end{array}$ \\
\hline Log(tasa de desempleo/100) & $-0,115$ & $-0,135$ & $-0,250$ \\
& $(-6,58)$ & $(-8,24)$ & $(-13,65)$ \\
\hline
\end{tabular}

Fuente: Elaboración propia a partir de cifras de la Encuesta Permanente de Hogares del INDEC.

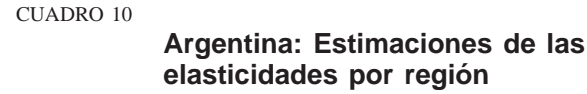

\begin{tabular}{|c|c|c|}
\hline \multirow[b]{2}{*}{ Variable } & \multicolumn{2}{|c|}{ Remuneraciones horarias } \\
\hline & $\begin{array}{c}\log (\text { tasa de } \\
\text { desempleo/100) }\end{array}$ & $\begin{array}{l}\text { Duminic*log(tasa } \\
\text { de desempleo/100) }\end{array}$ \\
\hline \multirow[t]{2}{*}{ Toda la muestra } & $-0,073$ & 0,026 \\
\hline & $(-22,95)$ & $(19,23)$ \\
\hline \multirow[t]{2}{*}{ Gran Buenos Aires } & $-0,120$ & 0,036 \\
\hline & $(-9,71)$ & $(8,11)$ \\
\hline \multirow{2}{*}{ Córdoba } & $-0,100$ & 0,057 \\
\hline & $(-7,75)$ & $(11,65)$ \\
\hline \multirow[t]{2}{*}{ Jujuy } & $-0,092$ & 0,021 \\
\hline & $(-6,59)$ & $(3,97)$ \\
\hline \multirow[t]{2}{*}{ La Pampa } & $-0,119$ & 0,030 \\
\hline & $(-10,64)$ & $(7,71)$ \\
\hline \multirow[t]{2}{*}{ La Plata } & $-0,063$ & 0,030 \\
\hline & $(-3,81)$ & $(5,53)$ \\
\hline \multirow[t]{2}{*}{ Mendoza } & $-0,301$ & 0,046 \\
\hline & $(-10,38)$ & $(8,84)$ \\
\hline \multirow[t]{2}{*}{ Neuquén } & $-0,325$ & 0,059 \\
\hline & $(-5,86)$ & $(4,76)$ \\
\hline \multirow[t]{2}{*}{ Rosario } & $-0,175$ & 0,052 \\
\hline & $(-5,34)$ & $(7,09)$ \\
\hline \multirow[t]{2}{*}{ Salta } & $-0,169$ & 0,016 \\
\hline & $(-7,37)$ & $(2,62)$ \\
\hline \multirow[t]{2}{*}{ Santa Cruz } & 0,017 & 0,016 \\
\hline & $(0,85)$ & $(4,81)$ \\
\hline \multirow[t]{2}{*}{ Tucumán } & $-0,034$ & 0,035 \\
\hline & $(-0,80)$ & $(3,80)$ \\
\hline
\end{tabular}

Fuente: Elaboración propia con datos de la Encuesta Permanente de Hogares del INDEC.

se estima para toda la muestra, sin incluir las variables ficticias por núcleo urbano, las elasticidades resultantes siguen siendo significativas, pero menores que cuando se consideran los efectos fijos.

\section{b) La curva de remuneraciones en la fase de recuperación}

En el apartado anterior analizamos la relación entre los salarios y la tasa de desempleo en el período de convertibilidad. Aquí aplicamos una metodología semejante para examinar la fase de recuperación reciente, basándonos en información proveniente de la EPH continua realizada en 2003 y el primer semestre de 2004. Al igual que en el caso anterior, las estimaciones no rechazan la asociación entre las variaciones de los salarios y el desempleo. En este caso, los incrementos de los salarios reales se asocian con la reducción de las tasas de desempleo.

La relación entre los cambios en los salarios y las tasas de desempleo se examina en sus dimensiones temporal y geográfica. La dispersión regional de los aumentos salariales y la concomitante evolución 
diferenciada de las tasas de desempleo en el período enriquecen la información disponible para poner a prueba la hipótesis.

El modelo estimado es similar al del apartado anterior. Supone que el salario del trabajador $i$ depende de las características individuales (la región en que trabaja, la educación que posee, el sector al que pertenece su actividad, el tamaño de la empresa, el sexo, la edad) y de la tasa de desempleo de la región de pertenencia en el momento en que es recogida la información. La presencia de las variables ficticias regionales en las estimaciones recoge los efectos fijos de diferencias interregionales en los niveles de los salarios.

Además de las estimaciones para todo el país, realizamos estimaciones en cada una de las regiones estudiadas. En estas estimaciones las variables de control son la educación, el sector, el tamaño de la empresa, el sexo y la edad.

Realizamos estimaciones por separado en los casos de trabajadores registrados y no registrados. Además, presentamos estimaciones correspondientes a otras categorías de trabajadores (por ejemplo, por cuenta propia) para mostrar que la evolución de sus ingresos también estuvo asociada con los indicadores de cambios en el mercado de trabajo.

El cuadro 11 muestra las elasticidades estimadas de alcance nacional y de cada una de las regiones consideradas, para los grupos constituidos por los trabajadores registrados y los no registrados. Las elasticidades son significativas al $1 \%$, excepto cuando se indica otra cosa.

Todas las elasticidades regionales estimadas son altamente significativas en el caso de los trabajadores
CUADRO 11

\begin{tabular}{lcc} 
& \multicolumn{2}{c}{$\begin{array}{c}\text { Argentina: Elasticidades-desempleo de } \\
\text { trabajadores registrados }\end{array}$} \\
\multicolumn{1}{c}{ Región } & $\begin{array}{c}\text { Elasticidades } \\
\text { (trabajadores } \\
\text { registrados) }\end{array}$ & $\begin{array}{c}\text { Elasticidades } \\
\text { (trabajadores no } \\
\text { registrados) }\end{array}$ \\
\hline Gran Buenos Aires & $-0,34$ & $-0,46$ \\
Cuyo & $-0,45$ & $-0,49$ \\
NEA & $-0,48$ & $-0,34$ \\
NOA & $-0,56$ & $0,00^{\mathrm{a}}$ \\
Pampeana & $-0,40$ & $0,00^{\mathrm{a}}$ \\
Patagonia & $-0,29$ & $-0,33$ \\
Total & & $-0,461$ \\
\hline
\end{tabular}

Fuente: Elaboración propia a partir de cifras de la Encuesta Permanente de Hogares del INDEC.

a No significativa.

registrados. Para el conjunto de estos trabajadores la elasticidad estimada es $-0,34$, altamente significativa. Esta elasticidad implica que una caída de $10 \%$ en la tasa de desempleo (por ejemplo, una contracción de 1,5 puntos porcentuales de la población activa, si la tasa de desempleo es $15 \%$ ) representa un aumento de salario de $3,4 \%$.

En el caso de los trabajadores no registrados, las elasticidades son significativas a nivel nacional y en las regiones, salvo en las regiones NOA y Pampeana. Esto es congruente con que en estas dos últimas regiones las variaciones estimadas de los salarios de los trabajadores no registrados resultan muy pequeñas.
Altimir, O. y L. Beccaria (2000): Distribución del ingreso en la Argentina, en D. Heymann y B. Kosacoff (comps.), La Argentina de los noventa, Buenos Aires, EUDEBA/CEPAL.

Beccaria, L. y R. Maurizio (2001): Movilidad laboral e inestabilidad de ingresos en Argentina, Buenos Aires, Universidad Nacional de General Sarmiento.

Blanchflower, D.G. y A.J. Oswald (1996): The Wage Curve, Cambridge, Massachusetts, The MIT Press.

Damill, M. y R. Frenkel (2003): Las medidas recientes de política salarial y el contexto macroeconómico, documento preparado para la OIT y el Ministerio de Trabajo, Empleo y Seguridad Social, Buenos Aires, Centro de Estudios de Estado y Sociedad (CEDES), inédito.

(2005): Argentina: macroeconomic performance and crisis, en R. Ffrench-Davis, D. Nayyar y J.E. Stiglitz (comps.), Stabilization Policies for Growth and Development, Nueva York, Initiative for Policy Dialogue/Macroeconomics Task Force, por aparecer.
Damill, M., R. Frenkel y L. Juvenal (2003): Las cuentas públicas y la crisis de la convertibilidad en Argentina, Desarrollo económico, vol. 43, № 170, Buenos Aires, Instituto de Desarro1lo Económico y Social (IDES).

Damill, M., R. Frenkel y R. Maurizio (2002): Argentina: A Decade of Currency Board. An Analysis of Growth, Employment and Income Distribution, Employment Paper No 2002/42, Ginebra, Oficina Internacional del Trabajo.

(2003): Políticas macroeconómicas y vulnerabilidad social: la Argentina en los años noventa, serie Financiamiento del desarrollo, No 135, LC/L.1929-P, Santiago de Chile, Comisión Económica para América Latina y el Caribe (CEPAL). Publicación de las Naciones Unidas, $\mathrm{N}^{\circ}$ de venta: S.03.II.G.84.

Damill, M., R. Frenkel y M. Rapetti (2005): La deuda argentina: historia, default y reestructuración, Desarrollo económico, vol. 45, No 178, Buenos Aires, Instituto de Desarrollo Económico y Social (IDES), julio-septiembre. 
Frenkel, R. (2003a): Globalización y crisis financieras en América Latina, Revista de la CEPAL, No 80, LC/G.2204-P, Santiago de Chile, Comisión Económica para América Latina y el Caribe (CEPAL).

(2003b): From the Boom in Capital Inflows to Financial Traps, Barcelona, Initiative for Policy Dialogue, Capital Market Liberalization Task Force, junio.

(2005): Remuneraciones, mercado de trabajo y política salarial en la recuperación. Argentina 2003-2004, documento preparado para la OIT y el Ministerio de Trabajo, Empleo y Seguridad Social, Buenos Aires, Centro de Estudios de Estado y Sociedad (CEDES), inédito.

Frenkel, R. y M. González Rozada (2000a): Argentina: balance of payments liberalization, effects on growth, employment and income, en L. Taylor (comp.), External Liberalization, Economic Performance and Social Policy, Oxford, Oxford University Press.

(2000b): Tendencias de la distribución de ingresos en los años noventa, Buenos Aires, Universidad de Palermo/Centro de Estudios de Estado y Sociedad (CEDES).

Taylor, L. (1998): Lax Public Sector, Destabilizing Private Sector: Origins of Capital Market Crises, International Monetary and Financial Issues for 1990s, vol. 10, Nueva York, Conferencia de las Naciones Unidas sobre Comercio y Desarrollo (UNCTAD).

Tokman, V. y D. Martínez (comps.) (1999): Productividad y empleo en la apertura económica, Lima, Organización Internacional del Trabajo (OIT). 